BY ABBIE TURIANSKY

\title{
Collective Action in Games as in Life: Experimental Evidence from Canal Cleaning in Haiti
}

November 2017 


\section{ABSTRACT}

When the provision of public goods depends on voluntary contributions, informal institutions and social norms can play an important role in increasing contributions. I explore the impact of exposure to a collective action dilemma in a framed public goods game on farmers' behavior in real-world scenarios in which they face similar strategic trade-offs. Among 875 rice farmers who were part of an agricultural technology adoption study in rural Haiti, I randomly selected 300 to participate in public goods games framed to mimic the real trade-off they face between private work and participation in the management of shared canals. Over the subsequent planting season, the local irrigation association organized voluntary canal-cleaning work days to manage the shared canal systems that irrigate farmers' fields. Treated farmers were $47 \%$ more likely than the control group to volunteer. The mechanism through which the treatment seemed to operate was by shifting participants' expectations of others' contributions to the public good, suggesting that public goods games provide a setting in which to learn about one's neighbors and develop common norms of behavior. 


\section{INTRODUCTION}

The important role that local institutions, formal and informal, play in shaping development outcomes is widely recognized. A growing literature links social capital and norms to a range of development challenges, from management of shared resources to group lending to sanitation behavior. Many researchers have analyzed the characteristics of successful decentralized management of common-pool resources such as irrigation systems (Ostrom 1990; Cárdenas et al. 2011; McCarthy et al. 2001; Baland and Platteau 1998). These characteristics include formal local management institutions with rules and enforcement mechanisms as well as informal institutions such as social norms around cooperation and resource use. Although the literature has improved our understanding of the types of norms and institutions that are correlated with successful resource management, the study of how to encourage and strengthen such institutions is complicated by the lack of exogenous variation in drivers of institution formation. Improving our understanding of how norms and institutions form and evolve is of great policy relevance, because interventions and development policies aim to encourage collective action through strengthening local institutions.

In this study I asked whether exposure to a collective action problem in a controlled setting can change real-world behavior in a scenario in which the same strategic considerations are relevant. I randomly assigned participants to play public goods (PG) games to study whether such exposure may shift farmers' beliefs or understanding of a local public goods provision problem and ultimately move real-world behavior toward more socially optimal levels. The use of a lab-in-the-field experimental game as a source of exogenous variation provides a unique contribution to the literature on decentralized management of public goods, as well as to the experimental and behavioral economics literature, by demonstrating that games can shift beliefs and lead to changes in individual contributions to a public good.

I found that farmers who participated in a PG game, framed to replicate the coordination problem they face managing shared irrigation infrastructure, were $47 \%$ more likely to contribute to canal management during the subsequent planting season. This finding suggests that such labin-the-field experimental games may be useful not only to study in-game behavior as an outcome of interest but also to shift behavior outside the games. Further, I found evidence suggesting that one mechanism through which the treatment operates is by an effect on participants' expectations of others' contributions to the public good. Behavioral games provide an opportunity for participants to learn about the social and technological context in which the public good is provided, and this context includes the behavior one can expect of other beneficiaries of the public good. The increase in real-world public good contributions, primarily among participants who learn that their neighbors are likely to contribute, suggests a desire to conform to a norm of contribution levels, and that games provide a setting through which individuals can learn about and develop common norms.

I conducted the games with rice farmers in Haiti who depend on a shared irrigation system that lacks a formal management system. Although the local irrigation association organizes farmers to contribute to management and cleaning, farmers report that participation is inadequate and that poorly functioning canals lower yields and increase flooding risk. This research context is a classic example of the "tragedy of the commons" (Hardin 1968), in which theory predicts 
that individuals acting in an uncoordinated manner will fail to reach a socially optimal level of the public good. Yet, in a variety of settings, individuals have overcome a collective action dilemma to establish norms, institutions, and rules to achieve a solution closer to the social optimum. For example, people everywhere vote, contribute to charities, and organize themselves to establish rules and norms of behavior for mutual benefit. There is extensive literature examining local institutions that have developed to manage shared resources and provide public goods (see Hess [1999] for an overview).

Although the literature provides us with examples and characteristics of local institutions capable of managing resources and providing public goods, we also know that such coordinated behavior fails in many settings. From a policy perspective, understanding how social institutions develop and evolve, and why we see such success in some settings and not in others, could provide valuable guidance for encouraging the formation and strengthening of local institutions and norms. Voors and Bulte (2014) suggest two primary pathways for institutional change: (1) change by design, whereby institutions are shaped by intervening outsiders or by strategic decisions of elites or (2) evolutionary change, in which systems of rules and norms emerge as a result of the uncoordinated choices of many agents. In the latter, individuals' expectations and beliefs change, either as a result of outside intervention or from some internal changes in beliefs, and these new beliefs and expectations change behavioral norms over time, gradually changing rules and constraints.

Many recent interventions have aimed to create or strengthen local institutions and governance and to involve communities in the development process, but most studies have failed to find that outside intervention can successfully change institutional quality through a top-down approach. Casey et al. (2012) found that a program targeting institutional quality had no impact on measures of fundamental social change such as collective action capacity and inclusion of marginalized groups. Labonne and Chase (2011) found that a community-driven development program in the Phillipines had a negative impact on collective action, despite its positive impact on participation in village assemblies. Similar interventions reported in Avdeenko and Gilligan (2014), Beath et al. (2013), Fearon et al. (2009), and Mansuri and Rao (2012) also yielded minimal evidence of institutional change. In contrast, in their study of post-conflict institutional quality in Burundi, Voors and Bulte (2014) found that changes in institutional quality seem to be explained by changes in beliefs and expectations rather than by outside design. This finding raises the question of how beliefs and norms change and whether they can be influenced by an external intervention.

Studies have appealed to people's sense of norms and social comparisons in an attempt to change behavior in a range of contexts, from smoking cessation to school performance to charitable giving. Many of these studies have found that such nonpecuniary strategies can lead to increased prosocial behavior, even in the absence of substantial personal benefit. For example, Ferraro and Price (2013) found that messages appealing to social norms and, in particular, comparisons with neighbors' behavior, reduced household water use, at least in the short run, and Allcott and Rogers (2014) found a similar result with respect to energy consumption.

The particular mechanism to influence individual behavior that I examine in this paper is the use of experimental games, framed to replicate the real situation in which cooperation is failing. A large number of laboratory experiments have demonstrated that people tend to contribute to 
public goods even when the rational prediction would be that they contribute nothing. In these experiments, researchers have repeatedly found that factors that should not change the theoretically predicted behavior-expectations of others' behavior, ability to communicate, and number of rounds played-correlated strongly and consistently with actual contributions (see Ledyard [1995] for an overview). There is some evidence that participants in laboratory and field experiments exhibit signs of learning over the course of repeated games, changing behavior over repetitions and even into other, similar games (Bó and Fréchette 2011; Duffy and Ochs 2009). Experimental games can expose participants to the strategic considerations of certain scenarios and prime them to behave differently in real-world scenarios in which the same considerations are relevant. When these games are framed to be relevant to farmers' experiences, they may make salient the importance of cooperative behavior and in turn lead to stronger resource management institutions.

The outcome of interest in this paper is participation in the cleaning and maintenance of the shared canal system, a public good that benefits all farmers whose plots are watered by the system. Experimental economics has traditionally focused on testing theories within controlled behavioral experiments, in which in-game behavior is the outcome of interest. Several recent studies (Karlan 2005; Hoff and Pandey 2006; Carter and Castillo 2011) have expanded the field to link behavioral measures elicited from lab-in-the-field experiments to economic outcomes, demonstrating the predictive power of behavioral experiments. In Karlan's 2005 study, players who exhibited more trustworthy in-game behavior repaid loans at a higher rate and saved more money, while those deemed by the games to be more trusting saved less and were more likely to drop out of a credit association. In several earlier studies, researchers conducted lab-in-the-field experiments and linked behavior from those experiments to community- and individual-level characteristics such as bargaining behavior, market integration, and community cohesion (Roth et al. 1991; Henrich et al. 2001; Barr 2003). These studies provide evidence that behavioral measures from experimental games can reliably predict real-world behavior in some settings.

The use of in-game behavior as an outcome in itself or as a predictor of real-world behavior implies that traits such as trustworthiness and altruism are individual characteristics and that the experimental games serve only as a measurement tool. However, if these games can provide participants with an opportunity to reflect on a problem they face in real life, they may serve as a pedagogical tool as well. Only one study of which I am aware has demonstrated behavioral change as a result of participation in a lab-in-the-field experiment. Cárdenas and Carpenter (2005) conducted a series of common-pool resource games with villagers who rely on a local common-pool resource, and they returned to the same villages between 6 and 20 months later to run the same games. They found that decisions in favor of a group-oriented outcome were significantly higher in the second round of games among both repeat participants and new participants. The researchers have anecdotal evidence that participants talked with their neighbors after the first round, so even those who did not participate in the first year had an opportunity to learn from the games through their neighbors. We do not know whether the behavioral change observed in the later games spilled over into behavior changes with regard to the real common-pool resource on which the villagers rely.

Although traditionally we think of surveys and field experiments solely as measurement tools, previous evidence has shown that being the subject of research can influence a 
participant's real-world behavior. In a study of several health and microlending projects, Zwane et al. (2011) found that being surveyed increased participants' take-up of medical insurance and use of water treatment technologies and thus may bias impact estimates. If we disregard the impact that data collection tools have on the behavior of those being studied, we risk biasing our results. On the flip side, we can recognize that tools traditionally used for data collection can play a role in intentionally influencing beliefs and changing behavior, as I do in this study. This paper provides new evidence that people's exposure to a coordination dilemma in the form of an artefactual lab-in-the-field experiment can change their behavior in a real-world situation in which they face the same strategies and trade-offs. In a setting in which institutions are weak, changing cooperative norms and encouraging participation in the provision of public goods may be instrumental in improving outcomes for farmers currently struggling with low availability of public goods. This research provides a possible mechanism for low-cost behavior change in a context in which higher levels of cooperation would raise welfare for the farmers involved.

\section{CONCEPTUAL FRAMEWORK}

In this section I present a simple model to illustrate the choice farmers make to allocate their private resources to a public good. I then use this model to examine the possible mechanisms through which the experimental intervention may change farmers' decisions over how much they allocate to the public good.

\section{Model}

Farmers divide their resources between cultivating his own plot and contributing to the public good. The public good in this context is the performance of the shared canals. When canals are clear of blockages and well graded, they allow for water to enter and leave the field as necessary and reduce the risk of flooding, thus raising average yields for all farmers who share the canal. Canal performance is a function of the aggregate contributions of all farmers. The farmer's private yields on his plot are a function of the resources he allocates to his farm and the performance of the canal.

Each farmer has a fixed endowment, $\omega_{i}$, that he can allocate between two inputs into farming: a private composite input, $x_{i}$, and his individual contributions, $z_{i}$, to a public good, $g$. The public good is a function of $Z=\sum_{i} z_{i}$, the total of all farmers' contributions: . $g=g(Z)=g\left(\sum_{i} Z_{i}\right)$ Yield $Y$ is a function of the private input and the performance of the canals: $Y_{i}=f\left(x_{i}, g(Z)\right)$. Yield is increasing and concave in both $x_{i}$ and $g(Z)$.

I assume in this model that farmers are uncertain about the functional forms specifying the relationships between resources allocated to the public good, performance of the canals, and farm yields. I use the notations $\tilde{f}_{i}$ and $\tilde{g}_{i}$ to denote the farmer's subjective yield production function and public goods production function, respectively.

The experimental literature has shown that, in both laboratory experiment settings and realworld behavior, contributions to public goods are frequently higher than would be predicted based only on the utility gained from the level of the public good (see, for example, Fischbacher 
et al. 2001; Isaac et al. 1994; Chaudhuri 2011). In other words, it is possible that people gain utility both through the level of a public good (in our case, through its impact on yields) and directly from their own individual contribution level. Andreoni (1990) coined the term warm glow to refer to the utility obtained from contributing to a common good, due to altruistic preferences or other personal benefit gained from giving to others. I assume that farmers' utility is a function of their expected farm yield and the utility they obtain directly from their own contribution to the public good; I model the function thus:

$$
U_{i}=U_{i}\left(\tilde{Y}_{i}, z_{i}\right)=\gamma_{i}\left(\tilde{f}_{i}\left(x_{i}, \tilde{g}\left(z_{i}+Z_{-i}\right)\right)\right)+\phi_{i}\left(z_{i}, \bar{z}, X_{-i}\right)
$$

where $U_{i}$ is concave and weakly increasing in both $Y_{i}$ and $z_{i}$. The $\gamma_{i}$ function is the utility a farmer obtains from his yields. The $\phi_{i}$ function is the utility obtained from his contribution to the public good, where $\bar{Z}$ is the average contribution from the other farmers and $X_{-} i$ is a vector of characteristics of all other farmers sharing the canals. $X_{-i}$ could also include variables characterizing other farmers' relationships to farmer $i$. These elements are included in the utility function because the utility a farmer attaches to his own contribution to the public good may depend on the behavior of others and on the characteristics of other beneficiaries of the public good.

The farmer's choice of allocation between his personal farm and the public good is represented in the following choice problem:

$$
\begin{gathered}
\max _{x_{i}, z_{i}} \gamma_{i}\left(\tilde{f}_{i}\left(x_{i}, \tilde{g}\left(z_{i}+Z_{-i}\right)\right)\right)+\phi_{i}\left(z_{i}, \bar{z}, X_{-i}\right) \\
\text { s.t. } x_{i}+z_{i}=\omega_{i}
\end{gathered}
$$

Solving the maximization problem yields the result that equates the marginal utility the farmer gains from allocating a unit of his endowment to each input. The marginal utility from $x_{i}$ derives simply through its effect on expected yields, while the marginal utility from $z_{i}$ is the sum of the direct utility he obtains from giving to the public good and the utility he gains through the effect of $z_{i}$ on expected yields:

$$
\frac{\partial \gamma_{i}}{\partial \gamma_{i}}\left(\frac{\partial Y_{i}}{\partial x_{i}}\right)=\frac{\partial_{i}}{\partial Y_{i}}\left(\frac{\partial \tilde{Y}_{i}}{\partial g_{i}(Z)} \frac{\partial \tilde{g}(Z)}{\partial z_{i}}\right)+\frac{\partial \phi_{i}}{\partial z_{i}}
$$

If a farmer obtains no utility from his own level of contribution to public goods and cares only about farm yield, the result simplifies to a standard problem of equating the marginal returns to yield of the private and public good:

$$
\frac{\partial Y_{i}}{\partial x_{i}}=\frac{\partial \tilde{Y}}{\partial g(Z)} \frac{\partial \tilde{g}(Z)}{\partial z_{i}}
$$




\section{Mechanisms for influencing contributions}

We can use this model to imagine possible pathways through which a person's contributions to the public good may be influenced in an intervention. I divide these mechanisms into two categories: technical and social, or behavioral. One way in which the experimental games may change behavior is by changing farmers' understanding of the technical or physical relationships between allocation of labor to canal maintenance, canal performance, and expected rice yields. The games could also allow farmers to learn something about the farmers with whom they share the canals, leading to a social learning effect that operates through the utility a farmer gains directly from his contribution to the public good.

1. Technical mechanism. The games may change farmers' understanding of or attention to either of the production functions:

a. The yield production function $Y_{i}=f\left(x_{i}, g(Z)\right)$. If the farmer's expected gains from the public good increase, for any given level of public good, an increase in $\frac{\partial Y_{i}}{\partial g(Z)}$ will require an increase in $\frac{\partial Y_{i}}{\partial x_{i}}$, which, given the assumption of diminishing marginal returns to $x_{i}$, will decrease the level of $x_{i}$ relative to $z_{i}$.

b. The public goods production function $g(Z)$. If the expected returns to contributions increase, as was the case for the expected returns to the public good, we would observe an increase in a farmer's contributions to the public good.

In both cases, the perturbation of the equilibrium provided by the experimental game is not to change the functions themselves but rather to shift participants' knowledge of the functions or their salience. A farmer may not understand well the importance of the public good in the production function for agricultural yields. If he is aware of its importance, he may still underweight it in his behavior if he is not actively conscious of the role of the public good in his production function; as a result, he might not fully understand the importance of coordination with his neighbors. The games may either change the farmer's understanding of these relationships or simply increase the salience in his mind. In either case, we would see a resulting change in behavior.

2. Social mechanism. The games may change the information a farmer has about other beneficiaries of the public good. Two types of information about others enter into the utility function - their contributions to the public good and their characteristics:

a. Expectations about others' contributions impact a farmer's expected utility in two ways:

i. The utility from yields, $\gamma_{i}\left(\tilde{f}_{i}\left(x_{i}, \tilde{g}\left(z_{i}+Z_{-i}\right)\right)\right)$, depends on others' contributions to the public good, $Z_{-i}$. If $g(Z)$ is nonlinear, the marginal returns of one farmer's contributions will depend on the total contributions from other farmers. If contributions from different farmers are substitutes, the expectation that others will contribute a lot could decrease one's own contributions-and vice versa, if contributions are complements. It is possible that the relationship is nonconvex, 
such that contributions could be substitutes or complements, depending on the overall contribution level. This would be the case, for example, if there are threshold effects: It may be that a certain level of contributions are required to clear large blockages in the canal system, so marginal returns to an hour of cleaning are low very far below or above this threshold. Regardless of the precise functional form, if $g(Z)$ is nonlinear, the marginal returns to farmer $i$ 's contributions will depend on the contributions of his neighbors.

ii. The utility related to one's own contributions, $\phi_{i}\left(z_{i}, \bar{z}, X_{-i}\right)$, also depends on others' contributions. An individual's direct utility from contributing may be related to a sense of conforming to a common norm. Individuals may not want to deviate too far from the norm, either in the positive or negative direction. A change in expectations of what others in the group are likely to contribute could, in this case, influence one's contributions in the direction of the norm.

b. One's perceptions of the characteristics of others who benefit from one's actions, $X_{-i}$, may shift because of the games. Other-regarding preferences depend on who benefits; for example, one may place more weight on the benefit to a neighbor or family member than one places on the benefit to a stranger. Any change in how one sees the others' benefitting from one's actions could change how much utility one gets from one's own contributions to the common good. We can represent such a shift as a change in $X_{-i}$, a flexible parameter that includes characteristics of other farmers as well as those farmers' relationships to farmer $i$.

\section{SAMPLE AND EXPERIMENTAL DESIGN}

\section{Context: Research area and population}

This study was conducted in conjunction with an agricultural development study designed to evaluate the household-level welfare impacts of the System of Rice Intensification (SRI) in Artibonite, Haiti. SRI is a cultivation method that has been shown to generate substantial and persistent increases in yield with low external input (Stoop et al. 2002; Sinha and Talati 2007). However, adoption has been lower than expected, given its apparent benefits, and disadoption has been observed in some locations (Moser and Barrett 2003; Takahashi and Barrett 2014). One possible explanation for the low adoption of SRI is its reliance on precise water management. Preliminary evidence in Haiti and elsewhere shows that poorly functioning irrigation systems are a substantial constraint to SRI adoption. In the absence of publicly provided infrastructure, the long-term success of the intervention may depend crucially on farmers' ability to establish a coordinated system to manage shared irrigation infrastructure. A key component of the research was to investigate ways in which such an institution may be encouraged among farmers.

The study takes place in the Artibonite Valley, the largest rice-producing region in Haiti. Farmers in the study cultivate land irrigated by a canal system that is managed by a local irrigation users' association, Association des Irrigants Liancourt Artibonite (AILA)—chosen for its conduciveness to the technology and the local implementing partner's history working with the local irrigation association. The irrigation system is complex, involving canals and drains at multiple scales, with different entities potentially responsible for the management at each scale. 
The irrigation system includes a large concrete canal and a series of gates connecting that canal to production blocks. A production block is defined as a set of plots of land that receive water from a single irrigation gate connected to the main canal. Blocks range in size from dozens to hundreds of hectares (ha) and can include between 200 and more than 1,000 farmers.

The local governmental agricultural office is responsible for maintaining the large system of concrete drains and canals, and AILA is responsible for maintaining the gates that feed the irrigation system within each block. Within a block, water is distributed to and drained from individual plots via a series of secondary, tertiary, and quaternary canals and drains. Most of these canals and drains serve many individual parcels, and farmers whose plots are not adjacent to a canal typically build small personal canals to connect to the shared system. No formal system currently exists for maintaining the canals and drains within the blocks. Individual canals are the responsibility of the farmer whose plot is served by the canal, but shared canals are maintained inconsistently, if at all. Farmers in the study region have provided anecdotal evidence of a previous common system for managing the shared canals. Under that system, farmers would come together in traditional workdays known as kombits, in which all were expected to participate.

Farmers report that currently the tradition of kombits has largely disappeared, and they provide several possible explanations. The population in the study region is relatively transient, and many landowners manage their plots from afar, hiring labor and visiting occasionally to work their farms. The absence of a stable population makes it more difficult to organize communal workdays, and absentee landowners are not likely to come to their plots to participate. Farmers and local implementing partners have also anecdotally linked the decline in kombits to the recent pattern of aid agencies, which aim to help farmers whose yields are dramatically hurt by poor water management by paying farmers to clean canals. Many farmers say they are unwilling to participate in voluntary communal work days because of the possibility that an external agent may pay them to do the very same work.

Kombits can be organized at multiple levels: (1) AILA or another farmers' association can organize kombits at the block level to clean the secondary canals that run through the entire block or (2) small groups of farmers can organize at a more local level for a section of canal that affects only a small number of parcels. In this study, I focus on block-level kombits organized by AILA. At the block level, canal cleanliness is fairly close to a pure public good: All farmers in the block benefit from it, regardless of their own contribution to its maintenance. At a more local level, the benefits of canal cleaning can be much more private. Farmers describe cleaning the portion of a smaller shared canal that runs by their own plot as primarily benefitting themselves, but with positive spillover effects on others: If the portion of the drain downstream from a farmer's plot is clean, it will help his drainage, but to a lesser extent. No local-level kombits were organized during the study period, so any canal cleaning that happened at the local level took the form of individuals cleaning near their own parcels, primarily benefitting their own plot, with positive spillovers on their neighbors. Given the frame of our experimental intervention as contributions to a public good, the block-level kombit better approximates the experimental frame than any canal cleaning done at a more local level. It is possible that any impact the intervention has on participation in canal cleaning could affect both levels, so we can view the impact on participation in the block-level kombit as a lower bound for the impact. 


\section{Sample and research timeline}

The sample for this study was drawn from the population of farmers who cultivated land in the irrigation system managed by AILA and who were eligible to participate in the agricultural technology adoption program described in section III.A. The program was implemented in four irrigation blocks, which local farmers' groups selected as most conducive to the agricultural technology being introduced in the program. Local implementing partners assisted in constructing a list of all farmers in the four blocks and a map of their parcels in each block. From this list, I randomly selected 250 farmers from each block to be included in the study sample. This selection was done at the farmer level, although approximately half of the farmers cultivated more than one parcel in the study area. The analytic sample for this paper includes the 875 farmers who agreed to participate in data collection efforts; participation rates were similar across the four blocks. The selection was drawn in January 2014 and baseline data were collected from participating farmers February-March 2014.

From the study sample, I randomly assigned farmers to the PG game treatment. Because the PG games were designed for farmers who cultivate neighboring plots to play together in a group, farmers were sampled on the basis of geographic clusters. To construct the sample, I used the parcel maps to create clusters of five neighboring parcels and randomly selected 60 of these clusters, 15 in each irrigation block, for the treatment group. Field guides were provided with lists of the farmers in the treatment clusters and told to find four of them for each group. This oversampling was necessary to ensure that there were four participants in each group, some farmers being unavailable to participate for various reasons. I discuss the analytical specifications used to correct for this oversampling in Section V.A. These groups of four farmers played the PG games in April 2014, following initial data collection and before the start of the planting season.

During the 2014 planting season, AILA organized periodic canal-cleaning work days, or kombits, between May and August 2014. Kombits were organized separately for each production block, with each block organizing 5 to 16 days of canal cleaning. Participation was optional, but all farmers were encouraged to participate. AILA collected names of all participants each day and provided farmers with a small stipend for each day they participated, to cover costs of transportation and food for the day. ${ }^{1}$

\section{Treatment: PG games}

The treatment consisted of a session of PG games played with farmers in April 2014. Each farmer participated in one session lasting two to three hours. Participants played in groups of four farmers who worked neighboring parcels, because the games were framed around cleaning canals shared with neighbors. Each session consisted of five groups of four. The setup and structure of the game were constant across all groups and sessions.

Farmers played a straightforward PG game in which they were each given ten chips, representing ten days of work, to allocate between a private payoff, framed as off-farm work, and

\footnotetext{
1 The stipend offered was lower than the typical daily wage that farmers in our sample would earn for the day, so farmers faced a real trade-off between participation in the kombit and real work.
} 
a shared payoff, framed as cleaning shared canals. The private activity yielded a constant ingame payoff of 200 gourdes (approximately \$5) per day, and the public activity yielded a payoff that depended on the aggregate contributions of all group members. If total contributions exceeded a threshold, the shared canals were clear and everyone in the group received a higher payoff from their rice fields; in the basic game, this higher payoff was 10,000 gourdes (approximately \$250). If total contributions fell short of the threshold, the shared canals were blocked and all participants received a lower payoff; in the basic game, the lower payoff was 8,000 gourdes (approximately \$200) from farming. See Table 1 for a full payoff matrix. The shaded cells in the payoff matrix correspond to situations in which the canals were "clear"; unshaded cells show those in which the canals were "blocked." In-game payoffs were divided by 100 to calculate real-life payoffs for participants, so that we could use realistic amounts for the in-game payoffs.

\section{Table 1. PG games payoff matrix: Simple game}

\begin{tabular}{|c|c|c|c|c|c|c|c|c|c|c|c|c|}
\hline \multirow[b]{2}{*}{$\begin{array}{l}\text { Player i's } \\
\text { contribution }\end{array}$} & \multicolumn{12}{|c|}{$\begin{array}{l}\text { Total contributions } \\
\text { from others }\end{array}$} \\
\hline & $0-14$ & 15 & 16 & 17 & 18 & 19 & 20 & 21 & 22 & 23 & 24 & $25-30$ \\
\hline 0 & 10000 & 10,000 & 10,000 & 10,000 & 10,000 & 10,000 & 10,000 & 10,000 & 10,000 & 10,000 & 10,000 & 12,000 \\
\hline 1 & 9,800 & 9,800 & 9,800 & 9,800 & 9,800 & 9,800 & 9,800 & 9,800 & 9,800 & 9,800 & 11,800 & 11,800 \\
\hline 2 & 9,600 & 9,600 & 9,600 & 9,600 & 9,600 & 9,600 & 9,600 & 9,600 & 9,600 & 11,600 & 11,600 & 11,600 \\
\hline 3 & 9,400 & 9,400 & 9,400 & 9,400 & 9,400 & 9,400 & 9,400 & 9,400 & 11,400 & 11,400 & 11,400 & 11,400 \\
\hline 4 & 9,200 & 9,200 & 9,200 & 9,200 & 9,200 & 9,200 & 9,200 & 11,200 & 11,200 & 11,200 & 11,200 & 11,200 \\
\hline 5 & 9,000 & 9,000 & 9,000 & 9,000 & 9,000 & 9,000 & 11,000 & 11,000 & 11,000 & 11,000 & 11,000 & 11,000 \\
\hline 6 & 8,800 & 8,800 & 8,800 & 8,800 & 8,800 & 10,800 & 10,800 & 10,800 & 10,800 & 10,800 & 10,800 & 10,800 \\
\hline 7 & 8,600 & 8,600 & 8,600 & 8,600 & 10,600 & 10,600 & 10,600 & 10,600 & 10,600 & 10,600 & 10,600 & 10,600 \\
\hline 8 & 8,400 & 8,400 & 8,400 & 10,400 & 10,400 & 10,400 & 10,400 & 10,400 & 10,400 & 10,400 & 10,400 & 10,400 \\
\hline 9 & 8,200 & 8,200 & 10,200 & 10,200 & 10,200 & 10,200 & 10,200 & 10,200 & 10,200 & 10,200 & 10,200 & 10,200 \\
\hline 10 & 8,000 & 10,000 & 10,000 & 10,000 & 10,000 & 10,000 & 10,000 & 10,000 & 10,000 & 10,000 & 10,000 & 10,000 \\
\hline
\end{tabular}

Payoffs were calibrated so that the social optimum was for the group to contribute the threshold amount, but the private payoff created an incentive for each individual to free-ride on the contributions of others. Because the threshold exceeded each individual's initial endowment, no individual could unilaterally contribute enough to ensure the higher rice yields, so coordination was necessary. These games were designed to simulate the real-life tradeoff between working for a private benefit and contributing to a public good in which benefits are shared.

In each round of the game, participants were asked whether they expected others in the group to give, on average, more than, less than, or the same as what they contributed to canal cleaning. The responses were used as measures of neighbors' expected cooperativeness. These measures were not incentive-compatible: Participants were not given any additional points for correctly anticipating their neighbors' behavior. ${ }^{2}$ However, farmers did predict fairly well, on

\footnotetext{
${ }^{2}$ Pretests showed that such an award system was difficult for farmers to understand and drew too much focus away from the primary decision making in the game.
} 
average, how their own behavior would compare with their neighbors', so this measure appears to be relatively valid.

Farmers played three different games during sessions. The first was a single-shot basic game with no communication, which can be thought of as a measure of initial propensity to cooperate in the provision of a public good. In the second game, farmers played repeated, independent rounds of the same basic game, presented as multiple rice seasons, with the ability to communicate between each round. Communication was verbal: Each group was given approximately one minute to discuss anything they wanted before making their decisions in private, although they were instructed not to make any promises or threats for actions to be taken outside of the game.

In the third game, rice payoffs were uncertain, dependent on a random weather shock. Payoffs were stochastic for both the clean and dirty canals, but the variance was higher when canals were dirty. The distribution of the payoffs was symmetric in both cases. The expected difference between the clean-canal payoff and the blocked-canal payoff was the same as in the nonstochastic game, so the expected returns to canal maintenance were held constant. When canals were clean, payoffs were 8,000,10,000, and 12,000 gourdes for bad, average, and good weather, respectively; when canals were dirty, payoffs were 5,000, 8,000, and 11,000 gourdes for bad, average, and good weather, respectively. This game was included to represent the importance of clean canals in reducing the negative impacts of weather shocks by reducing flood risk to improve the salience of the game as a learning tool.

At the end of the session, one round from each of the three games was chosen at random to determine final payoffs. This commonly used approach to game payoffs encourages participants to take each round of the game seriously because it could determine a large portion of the final take-home pay. Total payments ranged between approximately $150 \%$ and $250 \%$ of the typical daily agricultural wage in the region. All decisions and payments were kept private.

\section{DATA AND SUMMARY STATISTICS}

\section{Data sources}

I draw data from four sources:

1. The baseline household survey of all study participants, conducted February-March 2014, before implementation of the agricultural technology promotion program. Study participants were drawn randomly from all farmers included in the project. The household survey gathered information on agricultural activities, other economic activities, household demographics, and other baseline characteristics.

2. Game data from the PG games for all compliers in the treatment group - that is, those who were invited to the treatment and participated in the games

3. Canal-cleaning data that includes the names of all farmers who participated in kombits and the dates on which they participated. AILA gathered names of participants at the end of each week 
4. A follow-up survey conducted several months after the games, during the primary agricultural season, with the majority of study participants

\section{Summary of household baseline characteristics}

A balance test between the treatment and control group shows that the groups are well balanced on most household characteristics; only one variable-number of parcels cultivated in the study area-is statistically different, and the difference is small in magnitude. This test provides support for the integrity of the randomization process (see Table 2). The dummy variables for small commerce, household business, and salaried labor refer to whether anyone in the household participates in that economic activity (households may participate in more than one). Because income from small commerce or a household's business include both revenues and expenses, some households report negative nonfarm incomes as well as the more common negative farm incomes.

Table 2. Balance test on baseline characteristics between treatment and control groups

\begin{tabular}{|c|c|c|c|}
\hline & $\begin{array}{c}\text { (1) } \\
\text { Control }\end{array}$ & $\begin{array}{c}\text { (2) } \\
\text { Treatment }\end{array}$ & $\begin{array}{c}\text { (3) } \\
\text { (1) vs. (2), } \\
p \text {-value }\end{array}$ \\
\hline Age of household head & $\begin{array}{c}53.64 \\
(0.56)\end{array}$ & $\begin{array}{c}53.74 \\
(0.76)\end{array}$ & 0.92 \\
\hline Sex of household head (1 = male) & $\begin{array}{c}0.71 \\
(0.02)\end{array}$ & $\begin{array}{c}0.76 \\
(0.03)\end{array}$ & 0.14 \\
\hline Household size & $\begin{array}{c}4.76 \\
(0.10)\end{array}$ & $\begin{array}{c}4.92 \\
(0.15)\end{array}$ & 0.37 \\
\hline Education of household head & $\begin{array}{c}5.40 \\
(0.19)\end{array}$ & $\begin{array}{c}5.46 \\
(0.27)\end{array}$ & 0.85 \\
\hline Farm profit (1,000 HTG) per ha & $\begin{array}{c}56.35 \\
(17.13)\end{array}$ & $\begin{array}{c}67.15 \\
(15.68)\end{array}$ & 0.69 \\
\hline Nonfarm income (1,000 HTG) & $\begin{array}{l}121.58 \\
(27.30)\end{array}$ & $\begin{array}{l}125.69 \\
(27.33)\end{array}$ & 0.93 \\
\hline Total income (1,000 HTG) & $\begin{array}{c}172.84 \\
(31.19)\end{array}$ & $\begin{array}{l}190.36 \\
(31.61)\end{array}$ & 0.73 \\
\hline Off-farm enterprise (0/1) & $\begin{array}{c}0.65 \\
(0.02)\end{array}$ & $\begin{array}{c}0.66 \\
(0.03)\end{array}$ & 0.63 \\
\hline Salaried job (0/1) & $\begin{array}{c}0.15 \\
(0.01)\end{array}$ & $\begin{array}{c}0.17 \\
(0.02)\end{array}$ & 0.62 \\
\hline Wage labor (0/1) & $\begin{array}{c}0.05 \\
(0.01)\end{array}$ & $\begin{array}{c}0.05 \\
(0.01)\end{array}$ & 0.77 \\
\hline Number of parcels cultivated in study & $\begin{array}{l}1.82 \\
(0.05)\end{array}$ & $\begin{array}{l}2.03 \\
(0.09)\end{array}$ & 0.02 \\
\hline Total land cultivated (ha) & $\begin{array}{c}0.73 \\
(0.04)\end{array}$ & $\begin{array}{l}0.78 \\
(0.05)\end{array}$ & 0.47 \\
\hline Share of cultivated land owned & $\begin{array}{c}0.34 \\
(0.02)\end{array}$ & $\begin{array}{c}0.30 \\
(0.02)\end{array}$ & 0.29 \\
\hline Condition of drainage $(3=$ good $)$ & $\begin{array}{c}2.17 \\
(0.03) \\
\end{array}$ & $\begin{array}{c}2.20 \\
(0.05) \\
\end{array}$ & 0.56 \\
\hline $\mathbf{N}$ & 599 & 276 & \\
\hline
\end{tabular}

Standard errors in parentheses

Note: This table provides sample statistics on the farmers' baseline demographic characteristics and differences, between farmers selected for treatment and those in the control group. The dummy variables for small commerce, household business, and salaried labor refer to whether anyone in the household participates in that economic activity (households may participate in more than one). HTG = Haitian Gourdes (approximately $\$ 0.025$ at the time of the study). 
We need to be concerned about selection bias if, among those assigned treatment, compliers and noncompliers are systematically different. The two groups were found to be balanced on most observables, with several important differences (see Table 3). Several variables related to land cultivation and ownership are significantly different between the two groups, with compliers cultivating more parcels than noncompliers and noncompliers owning more land. I discuss later possible bias from unobservables that could come from farmers' self-selection into the treatment and correct for such a possibility using both intention-to-treat (ITT) and treatmenton-the-treated (TOT) methods.

We need to be concerned about selection bias if, among those assigned treatment, compliers and noncompliers are systematically different. The two groups were found to be balanced on most observables, with several important differences (see Table 3). Several variables related to land cultivation and ownership are significantly different between the two groups, with compliers cultivating more parcels than noncompliers and noncompliers owning more land. I discuss later possible bias from unobservables that could come from farmers' self-selection into the treatment and correct for such a possibility using both intention-to-treat (ITT) and treatmenton-the-treated (TOT) methods.

\section{Table 3. Balance test on baseline characteristics between compliers and noncompliers}

\begin{tabular}{|c|c|c|c|}
\hline & $\begin{array}{c}(1) \\
\text { Noncompliers }\end{array}$ & $\begin{array}{c}\text { (2) } \\
\text { Compliers }\end{array}$ & $\begin{array}{c}\text { (3) } \\
\text { (1) vs. (2), } p \text {-value }\end{array}$ \\
\hline Age of household head & $\begin{array}{l}53.68 \\
(2.10)\end{array}$ & $\begin{array}{c}53.75 \\
(0.81)\end{array}$ & 0.97 \\
\hline Sex of household head $(1=$ male $)$ & $\begin{array}{c}0.77 \\
(0.06)\end{array}$ & $\begin{array}{c}0.76 \\
(0.03)\end{array}$ & 0.96 \\
\hline Household size & $\begin{array}{l}4.60 \\
(0.35)\end{array}$ & $\begin{array}{c}4.99 \\
(0.16)\end{array}$ & 0.32 \\
\hline Education of household head & $\begin{array}{c}5.78 \\
(0.67)\end{array}$ & $\begin{array}{c}5.40 \\
(0.30)\end{array}$ & 0.60 \\
\hline Farm profit $(1,000$ HTG) per ha & $\begin{array}{c}66.21 \\
(35.89)\end{array}$ & $\begin{array}{c}67.34 \\
(17.45)\end{array}$ & 0.98 \\
\hline Nonfarm income (1,000 HTG) & $\begin{array}{c}44.02 \\
(22.20)\end{array}$ & $\begin{array}{c}142.89 \\
(32.66)\end{array}$ & 0.17 \\
\hline Total income (1,000 HTG) & $\begin{array}{c}98.00 \\
(23.78)\end{array}$ & $\begin{array}{c}209.89 \\
(37.85)\end{array}$ & 0.18 \\
\hline Off-farm enterprise (0/1) & $\begin{array}{c}0.54 \\
(0.07)\end{array}$ & $\begin{array}{c}0.69 \\
(0.03)\end{array}$ & 0.05 \\
\hline Salaried job (0/1) & $\begin{array}{c}0.06 \\
(0.04)\end{array}$ & $\begin{array}{c}0.19 \\
(0.03)\end{array}$ & 0.03 \\
\hline Wage labor (0/1) & $\begin{array}{l}0.06 \\
(0.04)\end{array}$ & $\begin{array}{c}0.04 \\
(0.01)\end{array}$ & 0.58 \\
\hline Number of parcels cultivated in study & $\begin{array}{l}1.58 \\
(0.12)\end{array}$ & $\begin{array}{l}2.12 \\
(0.10)\end{array}$ & 0.02 \\
\hline Total land cultivated (ha) & $\begin{array}{c}0.66 \\
(0.14)\end{array}$ & $\begin{array}{c}0.81 \\
(0.05)\end{array}$ & 0.24 \\
\hline Share of cultivated land owned & $\begin{array}{c}0.35 \\
(0.07)\end{array}$ & $\begin{array}{c}0.29 \\
(0.03)\end{array}$ & 0.34 \\
\hline Condition of drainage $(3=$ good $)$ & $\begin{array}{c}2.29 \\
(0.11) \\
\end{array}$ & $\begin{array}{l}2.18 \\
(0.05) \\
\end{array}$ & 0.36 \\
\hline $\mathbf{N}$ & 48 & 228 & \\
\hline \multicolumn{4}{|l|}{ Standard errors in parentheses } \\
\hline \multicolumn{4}{|l|}{$\begin{array}{l}\text { Thistable providessamplestati } \\
\text { farmers selected for treatment, be }\end{array}$} \\
\hline
\end{tabular}




\section{Summary of PG games data}

Overall cooperation levels were high in all rounds of the PG games and increased as the game was repeated. The game was designed to make coordination challenging, by setting the threshold for reaching the higher rice profit at 25 days, a number not divisible by four. The efficient average contribution-that is, the minimum contribution necessary to reach the highyield threshold-was 6.25, which some groups achieved in a "fair" manner by each contributing 6 and taking turns, over the rounds, giving 7. Average contributions were slightly below the efficient level in the first round, at 6.19, but in all subsequent rounds the average was above 6.25. Mean contributions over the seven rounds of the second game were 6.49, and over the seven rounds of the third game, 6.70. Average contributions rose slightly over the 15 rounds (see Figure 1), but the increase is not statistically significant. The variance in contributions did not change over time.

Figure 1. Average individual contributions to the public good.

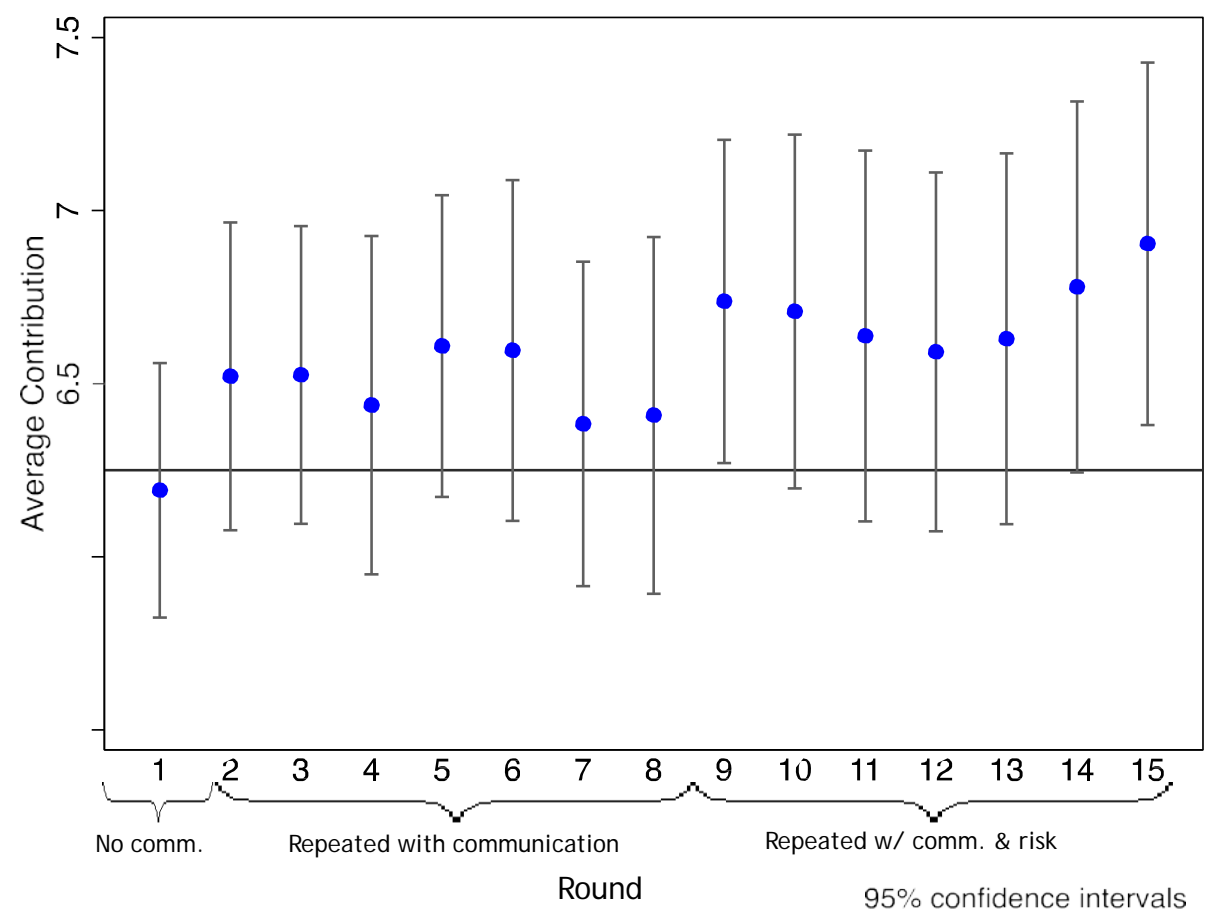

Note: $\quad$ This figure shows average contributions, with 95\% confidence intervals, for each round. Round 1 was the one-shot game with no communication; rounds 2-8 were the repeated game with verbal communication allowed between each round; rounds 9-15 were the repeated game with verbal communication and stochastic public goods payoffs.

As public goods contributions increased over rounds, average profits tended to increase as well, as the game was repeated. These findings are consistent with previous literature demonstrating learning over the course of coordination games. I also find that the correlation between a participant's contribution to the public good and the contributions of others in the group increased over time, which suggests improved coordination among group members over repetitions of the game. These findings suggest that, within the context of the game over time, farmers may have learned the role the public good played in their farm profits and learned more 
about how the other members of their group are likely to participate in the provision of the public good.

A more informative measure of successful cooperation than average contributions is the number of groups that cross the threshold between the low and high payoff, which I'll refer to as the cooperative threshold (see Figure 2). Here we also see improvement over time. In the first round, 55\% of groups successfully achieved or exceeded the cooperative contribution level. This number generally increased over the rounds, and in the final round $83 \%$ of groups crossed the threshold. In this case the number of groups achieving cooperation in each of the last four rounds was statistically different from the first round.

Figure 2. Share of groups achieving the cooperative threshold

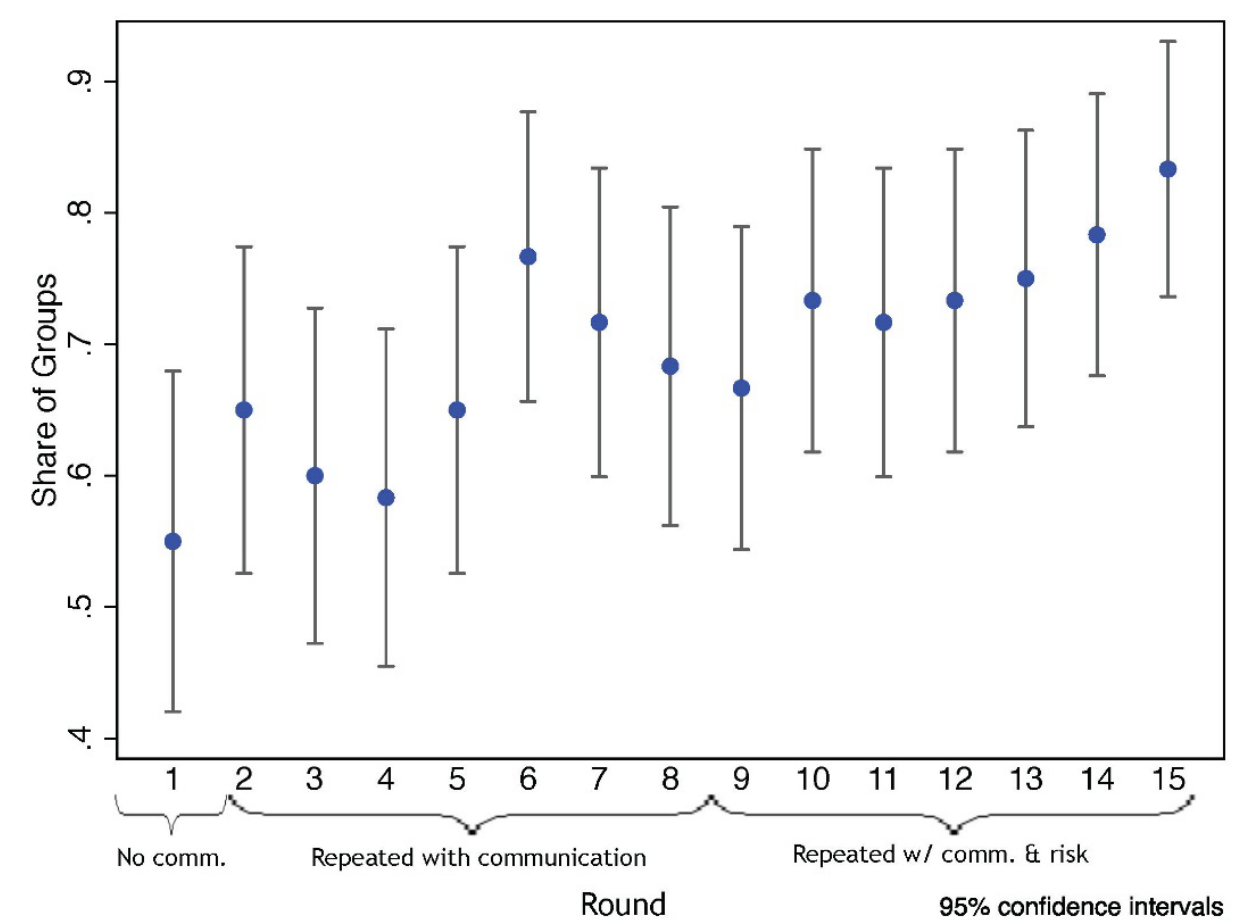

Note: $\quad$ This figure shows the share of groups that achieved the cooperative threshold, defined as the level of contributions to the public good that results in high payoffs from the public good for all participants. Round 1 was the one-shot game with no communication; rounds 2-8 were the repeated game with verbal communication allowed between each round; rounds 9-15 were the repeated game with verbal communication and stochastic public goods payoffs.

\section{Summary of canal cleaning data}

Of all of the households in the study, $11.5 \%$ participated in at least one day of canal cleaning during the planting season. Table 4 shows details on kombit participation of treated and control farmers, including a measure for whether or not farmers participated and measures of their level of participation. Not every farmer in our sample had the same opportunity to participate in the kombits, because each irrigation block organized its own cleaning schedule with a varying number of total days. This variation is due to differences in organizational capacity between the irrigation blocks as well as possible differences in the need for canal cleaning that arise from 
differences in drainage capacity and other physical characteristics. Another way to quantify a farmer's level of participation, which accounts for differences in opportunity to participate, is to calculate the share of canal cleaning days organized in the block in which the farmer participated.

Table 4. Kombit participation among treated and control farmers

\begin{tabular}{|c|c|c|c|}
\hline & $\begin{array}{c}\text { (1) } \\
\text { Control }\end{array}$ & $\begin{array}{c}\text { (2) } \\
\text { Treatment }\end{array}$ & $\begin{array}{c}\text { (3) } \\
\text { (1) vs. (2), } \\
\text { p-value }\end{array}$ \\
\hline Kombit (0/1) & $\begin{array}{c}0.09 \\
(0.01)\end{array}$ & $\begin{array}{c}0.14 \\
(0.02)\end{array}$ & 0.02 \\
\hline Kombit days & $\begin{array}{c}0.66 \\
(0.09)\end{array}$ & $\begin{array}{c}1.32 \\
(0.21)\end{array}$ & 0.00 \\
\hline Kombit share of possible days & $\begin{array}{c}0.06 \\
(0.01)\end{array}$ & $\begin{array}{c}0.11 \\
(0.02)\end{array}$ & 0.00 \\
\hline
\end{tabular}

Standard errors in parentheses

Note: $\quad$ This table shows participation in canal cleaning kombits for treated and control farmers. Kombit (0/1) is a dummy variable indicating whether a farmer participated in any canal cleaning. Kombit days is the number of days farmers participated in canal cleaning. Kombit share refers to the number of days that farmers participated as a share of the number of days that were organized in each farmer's irrigation block.

\section{EMPIRICAL RESULTS}

\section{The impact of PG games on canal cleaning}

The primary question about the impact of exposure to PG games on real-world contributions to public goods is simply whether those exposed to the games were more likely to participate in any kombits, or canal cleaning. To investigate this question, I estimated a linear probability model:

$$
K_{i}=\beta_{0}+\beta_{1} T_{i}+X_{i}^{\prime} \beta_{2}+\varepsilon_{i}
$$

where $K_{i}$ is a dummy variable indicating whether farmer $i$ participated in any kombits during the season, $T_{i}$ indicates whether the farmer was exposed to the PG games treatment, and $X_{i}$ is a vector of household controls. The household controls included are age of household head, sex of household head, household size, education of household head, farm profit, nonfarm income, number of parcels cultivated (total and in the study), land cultivated (total and in the study), share of parcels cultivated that are owned, and production block.

Because of the possible bias caused by noncompliance by some farmers assigned to the treatment group, I present both an ITT analysis and a TOT analysis using the invitation to participate as an exogenous instrument for participation. ${ }^{3}$ The compliance rate was $80 \%$. This rate is a result of the design, in which we invited five people for each group of four to ensure that

\footnotetext{
${ }^{3}$ For these measures, we have compliers, noncompliers (never takers), and those not offered treatment. Although those offered treatment had the option of not complying, that is, not participating in the games, those not offered treatment were not able to participate. As a result, we have no "always takers" in our population.
} 
the appropriate number of people would participate. For the ITT specification, I define $I_{i}$ to indicate whether farmer $i$ was invited to participate in the PG games:

$$
K_{i}=\beta_{0}+\beta_{1} I_{i}+X_{i}^{\prime} \beta_{2}+\varepsilon_{i}
$$

In the TOT analysis, I define as treated only those who received the treatment, that is, those who were invited and participated in the games. Selection into participation among those invited causes concern about endogeneity, because possible systematic differences between those who agree to participate and those who refuse could bias our results. I therefore conduct the TOT analysis using an instrumental variables approach, with the invitation to participate as the exogenous instrument:

$$
K_{i}=\beta_{1} \hat{P}_{i}+X_{i}^{\prime} \beta_{2}+\varepsilon_{i}
$$

where $\hat{P}_{i}$ is the predicted probability of participation in the games based on the first-stage regression: ${ }^{4}$

$$
P_{i}=\alpha_{0}+\alpha_{1} I_{i}+X_{i}^{\prime} \alpha_{2}+\varepsilon_{i}
$$

Results of both approaches are presented in Table 5, with the second column for each specification displaying results from regression models that include household controls. I present ITT results in columns 1 and 2 and TOT results, using invitation to participate as an instrument, in columns 3 and 4. Because treatment was implemented in groups of four neighboring farmers, standard errors in all analyses are clustered at the level of the group that played the game together. Control farmers have been assigned to geographic clusters of the same size as those in the treatment group, on the basis of the same maps that were used to create groups for the games. Such clustering allows us to correct for possible spatial correlation in errors, which could occur if local variation in water manageability or canal quality is correlated with the error.

The results show a weakly significant but substantial increase in the probability of participating in canal cleaning for farmers who participated in the PG games. Exposure to the games increased the likelihood of kombit participation by 5 to 6 percentage points, a substantial increase given the average participation rate of $11.5 \%$. The ITT results are approximately $20 \%$ smaller in magnitude than the TOT results, as expected given the take-up rate, with a similar significance level.

\footnotetext{
${ }^{4}$ The F statistics in the first-stage regression are 3476 and 182.5 with and without household controls, respectively.
} 
Table 5. Probability of kombit participation

\begin{tabular}{lcccc} 
Dependent variable Participation in kombits (0/1) & \multicolumn{2}{c}{ TOT (IV) } \\
& \multicolumn{2}{c}{ ITT } & $(2)$ & $(4)$ \\
PG games: Invited & $(1)$ & $0.042^{\star}$ & & \\
PG games & $0.055^{\star \star}$ & $(0.024)$ & $0.066^{\star \star}$ & $0.051^{\star}$ \\
Constant & $(0.026)$ & & $(0.032)$ & $(0.030)$ \\
Household controls & & 0.10 & $0.090^{\star \star \star}$ & 0.11 \\
\hline Observations & $0.090^{\star \star *}$ & $(0.078)$ & $(0.012)$ & $(0.078)$ \\
Adjusted $R^{2}$ & $(0.012)$ & Yes & No & Yes \\
\hline
\end{tabular}

Standard errors in parentheses

${ }^{*} p<.1,{ }^{* *} p<.05,{ }^{* *} p<.01$

Note: $\quad$ This table shows estimates of the probability of participating in any canal cleaning kombits as a function of the experimental treatment. TOT (IV) results use the invitation to participate as the instrument for treatment. Household controlsinclude age of household head, sex of household head, household size, education of household head, farm profit, nonfarm income, number of parcels cultivated (total and in the study), land cultivated (total and in the study), share of parcels cultivated that are owned, and production block.

\section{Intensity of kombit participation}

To examine the treatment effect in more detail, we can ask whether exposure to the PG games affects farmers' level of participation in the kombits. In this analysis, I focus on two outcome variables that measure the intensive margin of kombit participation. The first is the number of days a farmer spent cleaning canals, which ranges among participants from 5 to 16 . The second measure is the number of days spent cleaning as a share of the number of days organized in one's block, which accounts for the fact that farmers in different irrigation blocks were requested to participate for a different number of days.

With both of these measures, I use a Tobit model, in which we can think of our desired outcome variable $K_{i}^{*}$ as farmer $i$ 's propensity to participate in the kombits:

$$
K_{i}^{*}+\beta_{0}+\beta_{1} T_{i}+X_{i}^{\prime} \beta_{2}+\varepsilon_{i}
$$

but we only observe $K_{i}$, the farmer’s actual participation level:

$$
K_{i}=\left\{\begin{array}{ll}
K_{i}^{*} & \text { if } K_{i}^{*}>0 \\
0 & \text { if } K_{i}^{*} \leq 0
\end{array}\right\}
$$

The Tobit model accounts for the fact that all observations of zero are not equivalent. If we believe that those who participate in canal cleaning are somehow different from those who do not participate, a simple linear regression will not capture the distinction between participants and nonparticipants. Conceptually, we can think of a linear regression in this case as treating the distance between zero days of participation and one day the same as the distance between five and six days of participation. On the contrary, the move from zero days to one day is a move 
from nonparticipant to participant, so we need a model that treats positive values as fundamentally different from zero values. If we imagine that some nonparticipants are closer to participating than others, a small nudge toward participation may push the former group into participation while a bigger nudge would be required for the latter group. Mathematically, we can think of individuals with $E\left(K^{*} \mid T i=0\right)$ negative but close to zero being only a short distance from becoming contributors, so they will be more likely to respond to treatment by becoming contributors than individuals with $E\left(K^{*} \mid T i=0\right)$ large and negative. ${ }^{5}$

We cannot model the effect of the treatment on participation levels by looking only at those who participate, because selection into participation in the canal cleaning days is not random, as I showed in the first result. The treatment has a clear impact on whether or not one chooses to participate in canal cleaning and is likely to induce what we may call "marginal” participators into canal cleaning; these are farmers who would not have participated had they not been treated with the PG games. We would expect participation levels among these marginal participators to be lower than among always-participators (that is, those who would have participated regardless of treatment status). Therefore, we would expect the estimated treatment effect on participation levels among participants only-without accounting for the distinction between participants and nonparticipants — to be biased downward.

In this section, I present only an ITT analysis, because instrumental variables analysis is biased in a Tobit model with a binary endogenous regressor. The ITT measure is more conservative than the TOT measure, so we could consider the results to be a lower bound for the effect. The treatment has a large impact on the amount of time spent participating in kombits: approximately four days, or in the share model, one-third of the number of days organized in one's block. The results are presented in Table 6.

It is clear that, regardless of which outcome measure we use, exposure to the PG games leads to a substantial increase in kombit participation. What these results don't tell us, however, is why we observe the results we do. As discussed in Section II, there are several possible pathways through which exposure to the collective action dilemma in the lab-in-the-field experiment may lead to behavior change. In the next section, I examine possible mechanisms that could be driving the treatment effect.

\footnotetext{
${ }^{5}$ I choose a Tobit model rather than a Heckman-style selection model that specifies two distinct processes for the selection equation and the outcome equation because, in this context, there are no variables that can reasonably be excluded from the outcome equation, as required by a selection model. In some settings there are factors that influence the decision to participate but not the decision regarding how much to participate. The decision to participate in the job market, for example, may be influenced by fixed costs for searching for a job that do not affect the hours worked once one has joined the job market. In this setting, no such exclusion restrictions seem valid. For a robustness check, I conducted the same analysis using the Heckman model and the results were qualitatively similar.
} 


\section{Table 6. Level of participation in canal cleaning: Tobit model (ITT)}

\begin{tabular}{lcccc} 
& \multicolumn{2}{c}{ Kombit days } & \multicolumn{2}{c}{ Kombit share } \\
& $(1)$ & $(2)$ & $(3)$ & $(4)$ \\
PG Games: Invited & $4.50^{\star \star}$ & $3.39^{\star \star}$ & $0.36^{\star \star}$ & $0.27^{\star}$ \\
& $(1.77)$ & $(1.59)$ & $(0.15)$ & $(0.14)$ \\
Constant & $-19.7^{\star \star \star}$ & $-19.3^{\star \star \star}$ & $-1.65^{\star \star \star}$ & $-1.63^{\star \star \star}$ \\
& $(1.73)$ & $(6.04)$ & $(0.15)$ & $(0.51)$ \\
Household controls & No & Yes & No & Yes \\
\hline Observations & 875 & 839 & 875 & 839 \\
\hline
\end{tabular}

Standard errors (in parentheses) are clustered at the group level

${ }^{\star} p<.1,{ }^{\star *} p<.05,{ }^{* *} p<.01$

Note: $\quad$ This table presents estimates of the level of participation in canal cleaning kombits as a function of the experimental treatment. Columns 1 and 2 display as the outcome variable the number of days spent canal cleaning, while columns 3 and 4 show the number of days as a share of the total number of days organized in each farmer's canal. Household controls include age of household head, sex of household head, household size, education of household head, farm profit, nonfarm income, number of parcels cultivated (total and in the study), land cultivated (total and in the study), share of parcels cultivated that are owned, and production block.

\section{MECHANISMS}

We can use differences observed within the games as well as data from other surveys conducted with our sample to explore the reasons why we see the impact on kombit participation that we do. The setup of the game, framed to approximate the real relationship between canal cleaning and rice production, may teach farmers something about the technical, physical relationships among rice yields, canal functionality, and labor inputs into canal maintenance. Farmers may learn about the role of canal performance in the production function for rice$Y_{i}=f\left(x_{i}, g(Z)\right)$ - or about the role of time spent canal cleaning in the production function for canal performance, $g(Z)$. If this is the case, we can see the experimental treatment as a pedagogical tool to improve farmers' knowledge of the relevant production functions.

We can also think about the games as an opportunity to learn about a social technology. A key input into the functionality of a canal is the labor contributed by other farmers with whom one shares the canal. An individual's expectations of yields depends on his understanding of the technical production function as well as his expectations of the behavior of the others with whom he shares a canal. Participation in the games may affect a farmer's expectations if the games allow him to learn something about his plot neighbors. Finally, the utility that farmers obtain from contributing to a public good may depend on the characteristics of or his relationships with those with whom he shares the public good. The experiments provide a venue for learning more about those who benefit from his cooperative behavior, which could, in itself, influence his contributions.

In this section I explore technical and social mechanisms to provide some suggestive evidence of the mechanism driving the treatment effect. 


\section{Technical learning about the production functions}

One way the experimental treatment could influence behavior is by its acting as a pedagogical tool to improve understanding both of the trade-offs between private work and contributions to the public good and of the benefits of the public good: the yield production function- $Y_{i}=f\left(x_{i}, g(Z)\right)$ - or the production function of the public good itself, $g(Z)$. If participation in the games teaches treated farmers about the benefits of clean canals, this increased awareness should increase contributions to the public good.

Optimization of inputs into agriculture depends on knowledge of the production function, which is not known ex ante. There is a growing literature on how farmers learn about production functions, both from their own experience (Foster and Rosenzweig 1995) and from the experience of others (Besley and Case 1993; Conley and Udry 2001). These learning models typically assume that data, from either one's own farm or neighbors' farms, are the key inputs into learning. However, examples of individuals failing to assimilate all the available information into their understanding of production functions suggest that the availability of data is not sufficient for learning. In a model of incomplete learning, Hanna et al. (2014) show that farmers selectively choose which information to pay attention to when their production function depends on many inputs. Failing to notice a key input leads farmers to produce far below their productivity frontier despite the availability of data on the ignored input. In a similar manner, farmers in our study may, despite their experience and the availability of information on the role of water management in rice production, ignore its importance as an input when making their time allocation decisions. The PG games, by highlighting the importance of water management, may prime farmers to pay more attention to this input.

To examine whether the PG games served to increase understanding of the role of management in rice production, my research team asked farmers to estimate the production functions in order to compare responses between treatment and control farmers. In a follow-up survey conducted several months after the PG games, we asked farmers to estimate how their yields would change as a function of the performance of the canal running closest to their parcels. Farmers were able to estimate these differences without much trouble: Only a handful of farmers responded with "I don't know," and only one estimated higher yields when the canals were blocked than when they were clean. Figure 3 shows density curves for expected yields at each level of canal functionality, reported as the share of the maximum yield farmers expected when canals are at the highest level. Pairwise $t$-tests between means show that the mean for each level of canal performance is statistically different from each other level, which indicates some consistency among farmers in estimating the relationship between canal performance and expected yields.

If we hypothesize that the PG games changed kombit participation by changing something about farmers' understanding of the yield production function, we would expect to see differences in how canal performance affects expected yields between treatment and control farmers. I test whether this is the case with a flexible specification:

$$
\tilde{Y}_{i}=\beta_{0}+\sum_{k} \beta_{1 k} C_{k}+\beta_{2} T_{i}+\sum_{k} \beta_{3 k} T_{i}^{*} C_{k}+X_{i}^{\prime} \beta_{4}+\varepsilon_{i}
$$


where $\tilde{Y}_{i}$ is the farmer's subjective yield, as a share of the maximum possible yield; $C_{k}$ is the level of canal performance; and $T_{i}{ }^{*} C_{k}$ is an interaction term between treatment and the canal performance level. In this specification, each farmer has four observations: one for each canal performance level other than the highest level.

\section{Figure 3. Yield production function estimates}

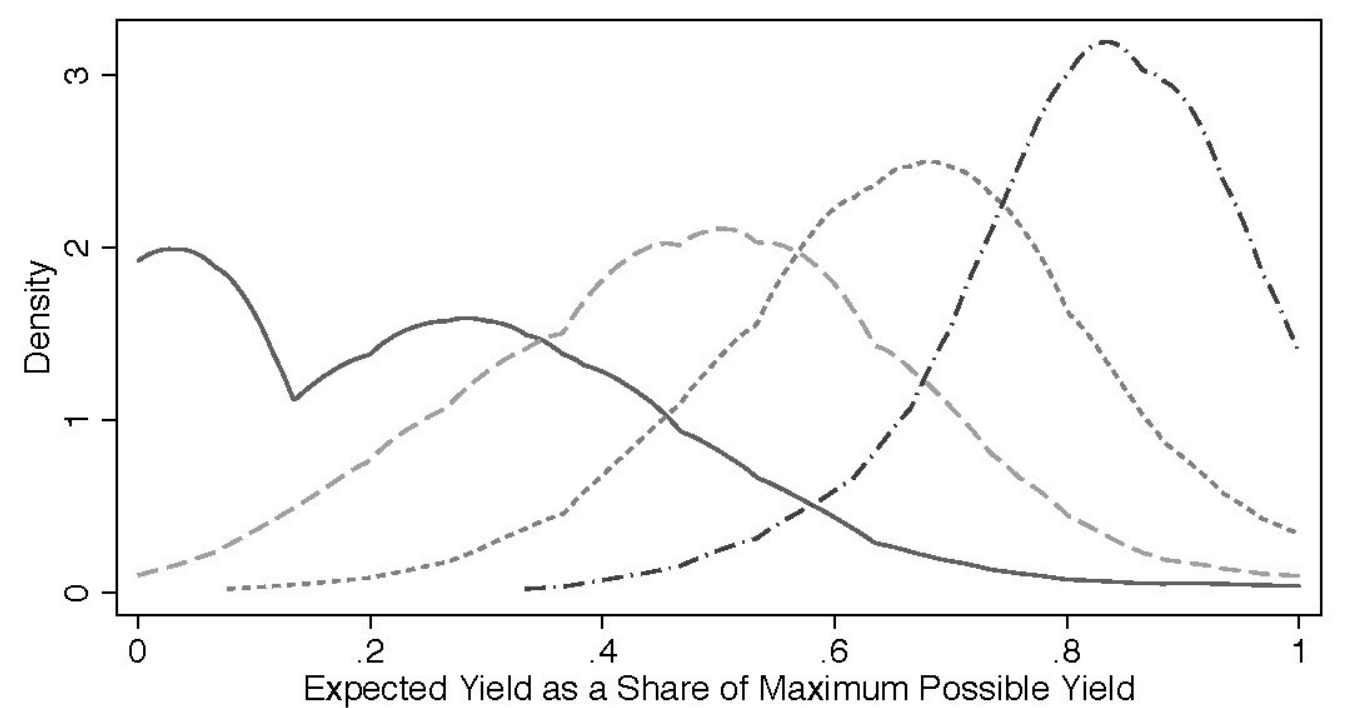

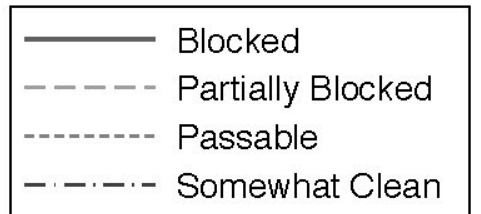

Note: $\quad$ Farmers estimated their expected yields on their main field for five levels of canal performance (blocked, partially blocked, passable, somewhat clean, and clean). This figure represents estimates for each level as a share of the expected yield when canals are at the cleanest level.

If the treatment changed farmers' perceptions of the effect of canal performance on yields, we would expect a significant coefficient on the interaction terms, $\beta_{1 k}$. Instead, we observe that although farmers attributed higher yields to better-performing canals (the coefficients $\beta_{3 k}$ are all positive and strongly statistically significant), we do not observe any difference between the treatment and control group (see Table 7). These results do not provide any evidence for a treatment effect on learning about the relationship between canals and yields. 


\section{Table 7. Yield estimates as a function of canal performance: Testing for treatment effect}

\begin{tabular}{|c|c|c|}
\hline Dependent variable: & $(1)$ & $(2)$ \\
\hline Partially blocked canal & $\begin{array}{c}0.25^{\star \star *} \\
(0.0096)\end{array}$ & $\begin{array}{c}0.25^{\star \star *} \\
(0.0098)\end{array}$ \\
\hline Passable canal & $\begin{array}{c}0.43^{\star \star \star} \\
(0.010)\end{array}$ & $\begin{array}{c}0.43^{\star \star *} \\
(0.011)\end{array}$ \\
\hline Partially clean canal & $\begin{array}{l}0.59 * \star \star \\
(0.011)\end{array}$ & $\begin{array}{l}0.59^{\star \star *} \\
(0.011)\end{array}$ \\
\hline Clean canal & $\begin{array}{l}0.76^{\star \star *} \\
(0.011)\end{array}$ & $\begin{array}{c}0.76^{\star \star *} \\
(0.012)\end{array}$ \\
\hline PG games: Invited & $\begin{array}{c}-0.029 \\
(0.018)\end{array}$ & $\begin{array}{c}-0.031^{*} \\
(0.018)\end{array}$ \\
\hline Partially blocked * $\mathrm{T}$ & $\begin{array}{c}0.0060 \\
(0.016)\end{array}$ & $\begin{array}{l}0.0077 \\
(0.016)\end{array}$ \\
\hline Passable * $T$ & $\begin{array}{l}0.0026 \\
(0.018)\end{array}$ & $\begin{array}{c}0.0062 \\
(0.019)\end{array}$ \\
\hline Partially clean * $T$ & $\begin{array}{c}0.014 \\
(0.018)\end{array}$ & $\begin{array}{c}0.016 \\
(0.019)\end{array}$ \\
\hline Clean * T & $\begin{array}{c}0.029 \\
(0.018)\end{array}$ & $\begin{array}{c}0.031^{\star} \\
(0.018)\end{array}$ \\
\hline Constant & $\begin{array}{c}0.24^{\star \star \star} \\
(0.011)\end{array}$ & $\begin{array}{c}0.17^{\star \star \star} \\
(0.034)\end{array}$ \\
\hline Household controls & No & Yes \\
\hline Observations & 3109 & 3014 \\
\hline Adjusted $R^{2}$ & 0.746 & 0.749 \\
\hline
\end{tabular}

Standard errors (in parentheses) are clustered at the group level

${ }^{\star} p<.1,{ }^{* *} p<.05,{ }^{* *} p<.01$

Note: $\quad$ Farmers estimated their expected yields on their main field for five levels of canal performance (blocked, partially blocked, passable, somewhat clean, and clean). This table shows estimates of the farmers' expected yields for each level as a share of the expected yield when canals are at the cleanest level.

We can also look at farmers' estimation of the public goods production function- that is, the performance of the canals as a function of the amount of time spent cleaning them. In the same follow-up survey, we asked farmers to estimate how many days each farmer in the production block would have to spend cleaning to bring a canal to a functional level, depending on its current level. A density curve for each initial cleanliness level is shown in Figure 4. Again, a $t$-test between each level shows that the mean number of days farmers estimate are required for each initial cleanliness level is statistically different; in other words, the number of days required to clean a blocked canal is statistically different from the number of days required to clean a somewhat blocked canal, and so on. 


\section{Figure 4. Public good production function estimates}

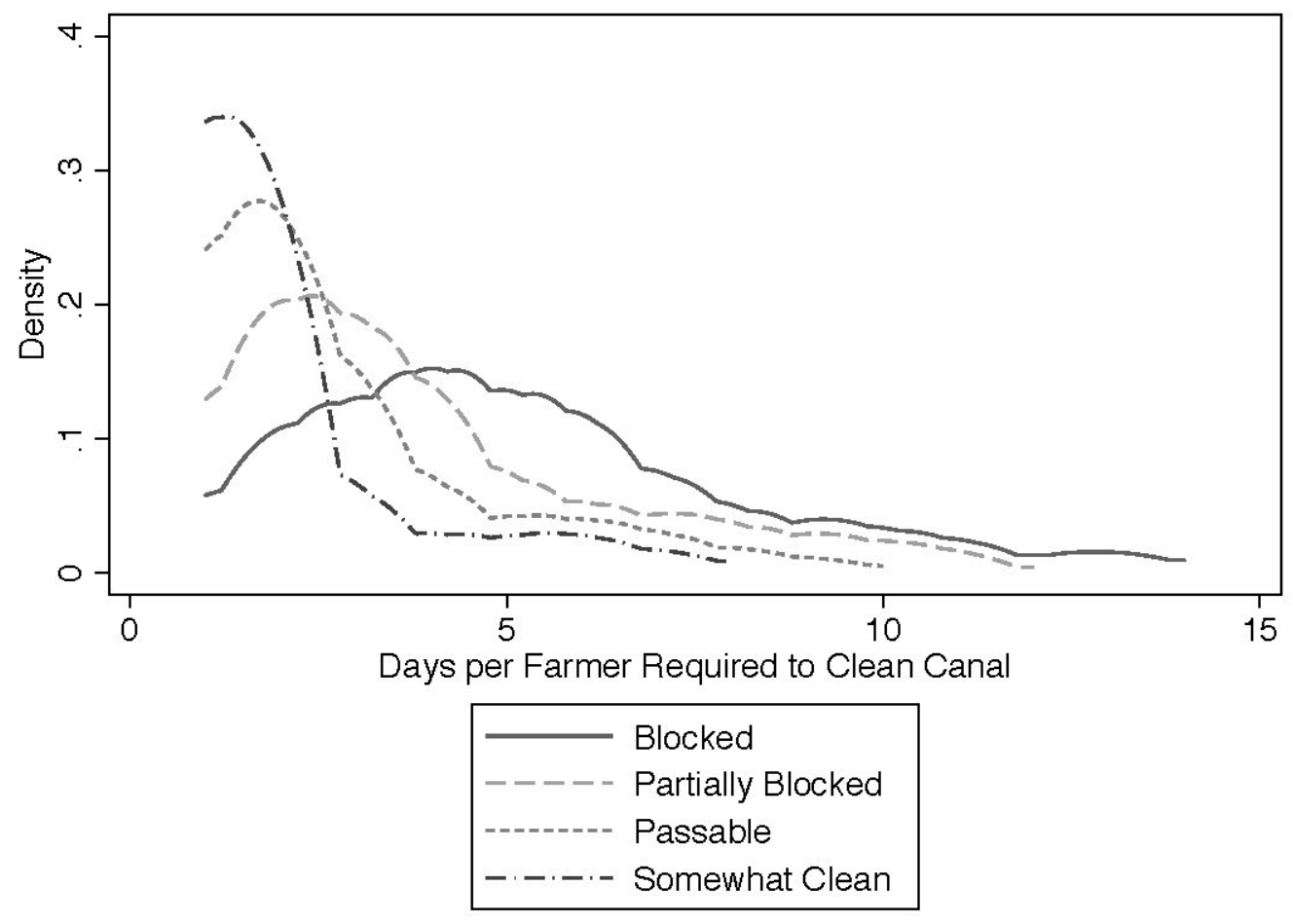

Note: $\quad$ Farmers estimated the labor require to clean canals from four different starting points (blocked, partially blocked, passable, and somewhat clean). This figure represents estimates for each level of canal cleanliness and tests whether the estimated relationship between yields and canal performance vary by treatment status.

As with the rice yield production function, if we think that the treatment changed farmers' understanding of the relationship between time spent cleaning the canals and their functionality, we would expect to see a difference between the treatment and control groups in this question. We can test this with a similar specification to the test of the yield production function:

$$
\tilde{D}_{i}=\beta_{0}+\sum_{k} \beta_{1 k} C_{k}+\beta_{2} T_{i}+\sum_{k} \beta_{3 k} T_{i}^{*} C_{k}+X_{i}^{\prime} \beta_{4}+\varepsilon_{i}
$$

where $\mathrm{D}_{i}$ is farmer $i$ 's estimate of the number of days of labor each person in the block would have to contribute to clean the canal, based on its initial level of cleanliness. If the PG games changed farmers' perceptions of the public goods production function, we would expect a significant coefficient on the interaction term. As with the yield production function, we observe a clear relationship between the days required to clean the canal and its initial cleanliness level, but we do not observe that this relationship depends on treatment status (see Table 8).

Although these results do not provide conclusive evidence that learning was not taking place, I cannot reject the null hypothesis that farmers who received the experimental treatment had the same understanding of both production functions as those in the control group. This result suggests that learning may not be the primary mechanism driving the observed treatment effect. 


\section{Table 8. Canal performance as a function of labor input: Testing for treatment effect}

\begin{tabular}{|c|c|c|}
\hline & (1) & (2) \\
\hline Partially blocked canal & $\begin{array}{c}-2.07^{\star \star *} \\
(0.10)\end{array}$ & $\begin{array}{c}-2.07^{\star \star *} \\
(0.11)\end{array}$ \\
\hline Passable canal & 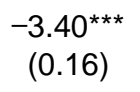 & $\begin{array}{c}-3.41^{\star \star \star} \\
(0.16)\end{array}$ \\
\hline Partially clean canal & $\begin{array}{c}-4.26^{\star \star * *} \\
(0.19)\end{array}$ & $\begin{array}{c}-4.29 * \star \star \\
(0.20)\end{array}$ \\
\hline PG games: Invited & $\begin{array}{c}-0.041 \\
(0.51)\end{array}$ & $\begin{array}{l}-0.12 \\
(0.51)\end{array}$ \\
\hline Partially blocked * $\mathrm{T}$ & $\begin{array}{l}0.072 \\
(0.19)\end{array}$ & $\begin{array}{l}0.081 \\
(0.20)\end{array}$ \\
\hline Passable * $T$ & $\begin{array}{c}-0.0021 \\
(0.34)\end{array}$ & $\begin{array}{l}0.013 \\
(0.34)\end{array}$ \\
\hline Partially clean * $T$ & $\begin{array}{l}0.027 \\
(0.43)\end{array}$ & $\begin{array}{l}0.058 \\
(0.43)\end{array}$ \\
\hline Constant & $\begin{array}{l}6.05^{\star \star \star} \\
(0.23)\end{array}$ & $\begin{array}{l}7.87^{\star \star \star} \\
(0.94)\end{array}$ \\
\hline Household controls & No & Yes \\
\hline Observations & 2477 & 2401 \\
\hline Adjusted $R^{2}$ & 0.200 & 0.227 \\
\hline
\end{tabular}

Standard errors (in parentheses) are clustered at the group level

${ }^{*} p<.1,{ }^{* \star} p<.05,{ }^{* *} p<.01$

Note: $\quad$ Farmers estimated the labor required to clean canals from four different starting points (blocked, partially blocked, passable, and somewhat clean). This table shows estimates of the farmers' expected labor requirements for each level of canal cleanliness and tests of whether the estimated labor requirements for canal cleaning vary by treatment status.

\section{Social learning about plot neighbors}

The link between social capital and collective action has been documented in many contexts, demonstrating that social bonds and norms can often be more effective tools for managing shared resources than formal rules and regulations (Sethi and Somanathan 1996; Pretty 2003; Ostrom 2014). Social capital has been defined in a number of ways, but it typically includes elements of social networks and social norms that enable people to act collectively. In this section I explore these two elements to study whether the experimental treatment had any effect on either norms or social networks and whether these characteristics affected behavior.

\section{Social norms}

If conforming to a behavioral norm is an important driver of one's decision to participate in canal cleaning, an important piece of information one may learn from participation in the games is what kind of behavior one can expect from one's neighbors. Participants who learn that their 
neighbors are unlikely to contribute to communal canal cleaning days may experience a different treatment effect than those who learn that their neighbors are likely to contribute.

To analyze the differential treatment effect by neighbors' contributions, I separate the treatment group into two groups based on the initial contributions of other members of the group during the PG games:

1. High-contribution treatment: I define $T H_{i}$ as a dummy variable indicating that the average contribution of all other members of farmer i's group (excluding i's own contribution) in the first round was above the optimal contribution. Recall that the optimal average contribution is 6.25 .

2. Low-contribution treatment: I define $T L_{i}$ as a dummy indicating that the average contribution of other members in the first round was below the optimum of 6.25.

For farmers in the treatment group, either $T H_{i}=1$ or $T L_{i}=1$ and, for farmers in the control group, $T H_{i}=T L_{i}=0$. With these new treatment variables, I use the following estimating equation:

$$
K_{i}=\beta_{0}=\beta_{1} T H_{i}+\beta_{2} T L_{i}+X_{i}^{\prime} \beta_{3}+\varepsilon_{i}
$$

In any analysis that includes behavior in the PG games as part of the treatment, we have to be concerned about endogeneity. Farmers who contributed more of their endowment to the public good during the games were found to contribute more time to canal cleaning in real life, but this is likely to be simply an indication that cooperative individuals cooperate more in both contexts. ${ }^{6}$ In this model I use the initial contributions of others in the group, because it is the only measure from the game that has not been influenced directly by the game behavior of other farmers in the group. After the first round, each participant's behavior may be in reaction to the behavior of others in the group, so all decisions made after the first round are at least partly endogenously determined. By considering only the initial contributions of others, we can divide the treatment group into two and get two separate treatment effects: the effect of playing the game with a group of high contributors and the effect of playing with a group of low contributors.

When we allow the treatment effect to vary by initial impressions of other group members' contributions, we see that the increase in real-world participation in kombits is present only for those whose group members are high contributors. Table 9 shows the result with the probability of any kombit participation as the outcome variable. For those who were in groups in which other group members contributed above the optimum, the increase in the probability of participating in kombits is higher than the initial result with all treated farmers grouped together.

\footnotetext{
${ }^{6}$ In a simple model estimating the probability of participation in kombits separately for treated farmers who contributed above the optimal contribution level on average and those who contributed below on average, I found that the former group is 10-11 percentage points more likely to participate in kombits, and I found no treatment effect for the latter group.
} 
For those in groups in which others contributed below the optimum, we do not see a statistically significant effect.

\section{Table 9. Treatment effect varies depending on initial contribution levels of others in group}

\begin{tabular}{lcc} 
Dependent variable: Participation in kombits (0/1) & & $(2)$ \\
Others above optimum & $(1)$ & $0.094^{\star *}$ \\
& $0.11^{\star \star \star}$ & $(0.041)$ \\
Others below optimum & $(0.042)$ & 0.035 \\
& 0.032 & $(0.034)$ \\
Constant & $(0.033)$ & 0.11 \\
& $0.088^{\star \star \star}$ & $(0.078)$ \\
Household controls & $(0.011)$ & Yes \\
\hline Observations & No & 839 \\
Adjusted $\mathbf{R}^{\mathbf{2}}$ & 875 & $\mathbf{0 . 0 4 6}$ \\
\hline
\end{tabular}

Standard errors (in parentheses) are clustered at the group level

${ }^{*} p<.1,{ }^{* \star} p<.05,{ }^{* \star *} p<.01$

Note: This table shows a re-estimation of the primary model testing the treatment effect on the probability of participation in kombits, with the treatment group separated into two groups: farmers in groups in which the average contributions of other group members in the first round were above the optimal contribution level and those in groups in which the average contributions were below the optimum.

We observe a similar result when we consider the level of kombit participation as the outcome variable: a strong, statistically significant relationship between the high-contribution treatment and level of participation, and little evidence of a relationship between the lowcontribution treatment and participation. I again use a Tobit model to examine the effect on the number of days of participation (see Table 10).

This finding suggests that expectations of others' participation in public goods provision may reveal the mechanism driving the treatment effect we see. As discussed in Section 2, information about others' behavior could matter if conforming to a norm is important to individuals. If one places value on contributing at a similar level to one's neighbors, learning that others are likely to contribute at a high level is likely to increase contributions. Learning about others' behavior could also matter if farmers believe that the return to their own contributions depends on the total contributions from others. In a follow-up survey during the planting season, farmers were asked to estimate the return to their contributions to canal maintenance if everyone else in the block was also participating in canal maintenance, compared to their return if nobody else was participating. Farmers told us that their efforts would make more of a difference if others were also contributing. An increase in contributions from farmers who learn that their neighbors are cooperative is consistent with an expectation that the returns to contributions are increasing in others' participation in canal maintenance. 
Table 10. Treatment effect varies depending on initial contribution levels of others in group (Level in participation: Tobit)

\begin{tabular}{|c|c|c|c|c|}
\hline & \multicolumn{2}{|c|}{ Kombit days } & \multicolumn{2}{|c|}{ Kombit share } \\
\hline & (1) & (2) & (3) & (4) \\
\hline Others above optimum & $\begin{array}{c}7.60^{\star \star \star} \\
(2.09)\end{array}$ & $\begin{array}{c}6.21^{\star \star \star} \\
(1.99)\end{array}$ & $\begin{array}{c}0.61^{\star \star \star} \\
(0.17)\end{array}$ & $\begin{array}{c}0.50^{\star \star \star} \\
(0.17\end{array}$ \\
\hline Others below optimum & $\begin{array}{c}3.12 \\
(2.48)\end{array}$ & $\begin{array}{c}3.01 \\
(2.33)\end{array}$ & $\begin{array}{c}0.26 \\
(0.21)\end{array}$ & $\begin{array}{c}0.24 \\
(0.20)\end{array}$ \\
\hline Constant & $\begin{array}{c}-19.6^{\star \star \star \star} \\
(1.70)\end{array}$ & $\begin{array}{c}-18.6^{\star \star \star} \\
(5.95)\end{array}$ & $\begin{array}{c}-1.65^{\star \star \star} \\
(0.14)\end{array}$ & $\begin{array}{c}-1.58^{\star \star \star \star} \\
(0.50)\end{array}$ \\
\hline Household controls & No & Yes & No & Yes \\
\hline Observations & 875 & 839 & 875 & 839 \\
\hline
\end{tabular}

Standard errors (in parentheses) are clustered at the group level

${ }^{*} p<.1,{ }^{* *} p<.05,{ }^{* * *} p<.01$

Note: In this table, I show the estimates of the treatment effect on the level of participation in kombits, using both measures of participation level (days and share of the total days organized in one's block) with the treatment group separated into two groups: farmers in groups in which the average contributions of other group members in the first round were above the optimal contribution level and those in groups in which the average contributions were below the optimum.

As a robustness check, we can examine whether farmers update their expectations about their neighbors' behavior on the basis of information gathered during the game about their expectations of others. In each round of the game, we asked farmers whether they expected their own contributions to the public good to be higher, lower, or the same as those of the other members in their group. I use these responses to define a learning variable indicating a positive (negative) shock if others' actual contributions were higher (lower) than expected, and a noshock variable if farmers were correct about their expectations. We can then run a model similar to the previous one, with the treatment separated into three groups: positive shock, no shock, and negative shock.

For this specification, I define three dummy variables:

1. Positive Shock: $S_{i}^{+}$indicates that others’ contributions were higher than expected.

2. Negative Shock: $S_{i}^{-}$indicates that others' contributions were lower than expected.

3. No Shock: $S_{i}^{0}$ indicates that others' contributions were the same as expected.

For farmers in the treatment group, $S_{i}^{+}=1, S_{i}^{-}=1$, or $S_{i}^{0}=1$ and for farmers in the control group, $S_{i}^{+}=S_{i}^{-}=S_{i}^{0}=0$. With these new treatment variables, my estimating equation is as follows:

$$
K_{i}=\beta_{0}+\beta_{1} S_{i}^{+}+\beta_{2} S_{i}^{-}+\beta_{3} S_{i}^{0}+X_{i}^{\prime} \beta_{3}+\varepsilon_{i}
$$

From this specification (see Table 11), we see that farmers who experience a positive information shock and update their expectations of others are more than twice as likely to 
participate in kombits as are control-group farmers, while the treatment effect is weaker for farmers who experience no information shock and absent for those who experience a negative information shock.

Table 11. Treatment effect varies depending on what participants learn about the contribution levels of others in group

\begin{tabular}{lcc} 
Dependent variable: Participation in kombits (0/1) & $(1)$ & $(2)$ \\
Positive shock & $0.10^{\star \star}$ & $0.095^{\star}$ \\
& $(0.052)$ & $(0.050)$ \\
No shock & $0.065^{\star}$ & 0.050 \\
& $(0.037)$ & $(0.036)$ \\
Negative shock & 0.048 & 0.055 \\
& $(0.052)$ & $(0.053)$ \\
Constant & $0.088^{\star \star \star}$ & 0.11 \\
& $(0.011)$ & $(0.078)$ \\
Household controls & No & Yes \\
\hline Observations & 875 & 839 \\
Adjusted $R^{2}$ & 0.009 & 0.044 \\
\hline
\end{tabular}

Standard errors (in parentheses) are clustered at the group level

$\mathrm{P}<.1,{ }^{\star *} \mathrm{p}<.05,{ }^{\star \star \star} \mathrm{p}<.01$

Note: This table shows my re-estimate of the primary model testing the treatment effect on the probability of participation in kombits with the treatment group separated into three subgroups: farmers who experience a positive information shock, learning that their neighbors contribute more than they had expected; farmers who experience a negative information shock; and farmers who experience no information shock.

While this analysis uses others' contributions only in the first round because of the concern about exogeneity of later behavior within the game, first-round behavior is a strong predictor of later behavior throughout the game, as shown in Table 12. We can see here that the probability of the group arriving at or above the optimal contribution level by the end of the game is significantly and positively correlated with first-round behavior. I use two different measures of first-round behavior: the total contribution level in the first game (shown in columns 1 and 2) and a dummy indicating whether or not the group contribution level was at or above the optimum in the first round (columns 3 and 4). Both measures provide similar results. 
Table 12. Final contributions as a function of first-round contributions

\begin{tabular}{|c|c|c|c|c|}
\hline Dependent variable: Final ro & $\begin{array}{l}\text { e optimum } \\
\text { (1) }\end{array}$ & (2) & (3) & (4) \\
\hline Total contributions: Game 1 & $\begin{array}{l}0.026^{\star \star \star} \\
(0.0051)\end{array}$ & $\begin{array}{l}0.023^{\star \star *} \\
(0.0052)\end{array}$ & & \\
\hline First round above optimum & & & $\begin{array}{l}0.51^{\text {** }} \\
(0.023)\end{array}$ & $\begin{array}{l}0.50^{\star \star \star} \\
(0.024)\end{array}$ \\
\hline Constant & $\begin{array}{l}0.055 \\
(0.13)\end{array}$ & $\begin{array}{l}0.053^{\star} \\
(0.27)\end{array}$ & $\begin{array}{c}0.047^{\star \star \star} \\
(0.022)\end{array}$ & $\begin{array}{l}0.55^{\star \star \star} \\
(0.066)\end{array}$ \\
\hline Household controls & No & Yes & No & Yes \\
\hline Observations & 228 & 221 & 875 & 839 \\
\hline Adjusted $\mathrm{R}^{2}$ & 9.095 & 0.187 & 0.348 & 0.367 \\
\hline
\end{tabular}

Standard errors (in parentheses) are clustered at the group level

${ }^{*} \mathrm{p}<.1,{ }^{* *} \mathrm{p}<.05, * * * \mathrm{p}<.01$

Note: This table shows the probability of the final round contributions in a group being above the optimum, dependent on either the total group contributions in the first round (Columns 1 and 2) or whether the group achieved a total above the optimum in the first round (Columns 3 and 4).

We can examine the in-game data on how farmers respond to others' behavior as further evidence of a propensity to conform to a common norm. Treating the within-game behavior as time series data, we can analyze how a farmer's contributions to the public good evolve over the rounds of the game in response to the contributions of others with a simple specification:

$$
P G_{i t}=\phi_{0}+\phi_{1} P G_{i t-1}+\phi_{2} O_{i t-1}+X_{i}^{\prime} \phi_{3}+\varepsilon_{i t}
$$

where $P G_{i t}$ is farmer $i$ 's contribution to the public good in time $t$ and $O_{i t}$ is the average contribution of other members of farmer i's group in time $t$. The estimation results are presented in Table 13. We see clearly that both the farmer's own behavior in previous rounds and the behavior of others are strong predictors of behavior in subsequent rounds.

This finding supports the assertion that the behavior of others is a driver of one's own behavior, which may explain why those who learn that the farmers with whom they share a canal are more cooperative within the game are in turn more likely to contribute at higher levels after the games are over. 
Table 13. In-game contributions over time

\begin{tabular}{lcc} 
Dependent variable: Contributions to PG in round $t$ & & \\
& & $(2)$ \\
Contributions to PG (t-1) & $0.57^{\star \star \star}$ & $0.58^{\star \star \star}$ \\
& $(0.036)$ & $(0.035)$ \\
Avg. PG contribution of other group members (t-1) & $0.24^{\star \star \star}$ & $0.21^{\star \star \star}$ \\
& $(0.043)$ & $(0.038)$ \\
Constant & $1.28^{\star \star \star}$ & $1.69^{\star \star \star}$ \\
& $(0.31)$ & $(0.52)$ \\
Household controls & No & Yes \\
\hline Observations & 3346 & 3094 \\
Adjusted $\mathrm{R}^{2}$ & 0.471 & 0.478 \\
\hline
\end{tabular}

Standard errors (in parentheses) are clustered at the group level

${ }^{*} p<.1,{ }^{* *} p<.05,{ }^{* * *} p<.01$

Note: $\quad$ This table shows a time series estimation of an individual's contributions in round $t$ as a function of that individual's contributions in the previous round as well as the average contributions of other group members in the previous round.

\section{Social networks}

A related potential social effect of the treatment is the social connectedness between farmers. The precise definition of social capital is heavily debated, but it typically includes elements of trust or norms as well as social networks. To explore this latter element, we surveyed farmers several months after the PG games to measure their level of connectedness to their plot neighbors.

Each farmer was asked about each other person in their geographic cluster whether the person is a plot neighbor, whether they ask the person for or give advice on farming matters, and whether they share labor. All of the people about whom these questions were asked were plot neighbors, according to our maps of the study area, so the first question is a test of whether the farmer knows that the other person farms a plot near them. It is possible for a farmer to answer yes to another social network question without knowing whether the farmer in question was a plot neighbor-31\% of farmers answered yes to at least one other question about another farmer they knew without identifying that person as a plot neighbor. Table 14 shows a summary of responses to the social networks questions for treated and control farmers, with a pairwise test of means between the two groups.

I define a social network variable for each question as the share of the other people in a farmer's group for whom the answer is yes to the question. I construct the variable as a share because the group size varied slightly. Most groups were five people, so each person was asked the social network questions about four others. If a farmer identified three of the other four as plot neighbors, the variable "Knows plot neighbors" is equal to 0.75 . Additionally, the variable "Any social network question" is the share of people in one's group for whom the farmer answered yes to at least one of the four questions. 
Table 14. Social networks: Summary and t-test

\begin{tabular}{lccc} 
& $\begin{array}{c}(1) \\
\text { Control }\end{array}$ & $\begin{array}{c}(2) \\
\text { Treatment }\end{array}$ & $\begin{array}{c}\text { (1) vs. (2), } \\
\text { p-value }\end{array}$ \\
Knows plot neighbors & 0.49 & 0.62 & 0.00 \\
Asks/gives farm advice & $(0.02)$ & $(0.02)$ & 0.00 \\
Shares labor & 0.42 & 0.56 & 0.02 \\
Any social network question & $(0.02)$ & $(0.02)$ & 0.00 \\
\hline $\mathrm{N}$ & 0.15 & 0.21 & \\
& $(0.01)$ & $(0.02)$ &
\end{tabular}

Standard errors (in parentheses)

Note: This table provides a pairwise t-test of self-reported social network variables, between farmers selected for treatment and those in the control group. Each variable is the share of the people in a farmer's geographic cluster for whom that farmer answered yes to that survey question.

To test the effect of the treatment on social connectedness, I run separate regressions of each social network variable on the treatment. The results are presented in Table 15. Here I present the ITT analysis, but the result is nearly identical for the TOT analysis, in which the invitation to participate is the instrument for participation. The effect of the treatment on social networks is strong: Participation in the games increases the share of people an individual identifies for each measure by approximately 50\%.

Table 15. Treatment effect on social networks

\begin{tabular}{|c|c|c|c|c|}
\hline & $\begin{array}{l}\text { Knows plot } \\
\text { neighbors } \\
\text { (1) }\end{array}$ & $\begin{array}{l}\text { Asks/gives farm } \\
\text { advice } \\
\text { (2) }\end{array}$ & $\begin{array}{c}\text { Shares labor } \\
\text { (3) }\end{array}$ & $\begin{array}{l}\text { Any soc. Net. } \\
\text { Question } \\
\text { (4) }\end{array}$ \\
\hline PG games: Invited & $\begin{array}{l}0.15^{\star \star \star} \\
(0.035)\end{array}$ & $\begin{array}{l}0.13^{\star \star \star} \\
(0.034)\end{array}$ & $\begin{array}{l}0.066^{\star \star} \\
(0.029)\end{array}$ & $\begin{array}{c}0.13^{\star \star} \\
(0.033)\end{array}$ \\
\hline Constant & $\begin{array}{c}0.35^{\star \star \star} \\
(0.11)\end{array}$ & $\begin{array}{c}0.030^{\star \star *} \\
(0.11)\end{array}$ & $\begin{array}{c}0.21^{\star \star} \\
(0.100)(\end{array}$ & $\begin{array}{c}0.42^{\star \star *} \\
(0.11)\end{array}$ \\
\hline Household controls & Yes & Yes & Yes & Yes \\
\hline Observations & 600 & 600 & 600 & 600 \\
\hline Adjusted $R^{2}$ & 0.076 & 0.062 & 0.027 & 0.053 \\
\hline
\end{tabular}

Standard errors in parentheses

${ }^{*} p<.1,{ }^{* \star} p<.05,{ }^{* \star *} p<.01$

Note: This table shows the treatment effect, using an ITT specification, on social connectedness. Each dependent variable is the share of the people in a farmer's geographic cluster for whom that farmer answered yes to that survey question.

As a robustness check, I looked at social connectedness of treated and control farmers before the games, asking similar social network questions at baseline. Although the questions were similar, they were asked of five randomly selected farmers in the production block, not specifically of parcel neighbors. Nonetheless, this check provides evidence that the treatment 
was uncorrelated with initial levels of social connectedness in general, so the higher responses to social network questions among treatment farmers appear to be caused by exposure to neighbors in the PG games (see Table 16).

Table 16. Social networks robustness check: Summary and $t$-test

\begin{tabular}{|c|c|c|c|}
\hline & $\begin{array}{c}(1) \\
\text { Control }\end{array}$ & $\begin{array}{c}\text { (2) } \\
\text { Treatment }\end{array}$ & $\begin{array}{c}\text { (3) } \\
\text { (1) vs. (2), } \\
\text { p-value }\end{array}$ \\
\hline Related & $\begin{array}{c}0.02 \\
(0.01)\end{array}$ & $\begin{array}{c}0.02 \\
(0.01)\end{array}$ & 0.72 \\
\hline Asks Farm Advice & $\begin{array}{c}0.03 \\
(0.010\end{array}$ & $\begin{array}{c}0.03 \\
(0.01)\end{array}$ & 0.80 \\
\hline Gives Farm Advice & $\begin{array}{c}0.03 \\
(0.01)\end{array}$ & $\begin{array}{c}0.03 \\
(0.01)\end{array}$ & 0.95 \\
\hline Shares Labor & $\begin{array}{c}0.02 \\
(0.00)\end{array}$ & $\begin{array}{c}0.02 \\
(0.01)\end{array}$ & 0.93 \\
\hline Any Soc. Net. Question & $\begin{array}{c}0.08 \\
(0.02)\end{array}$ & $\begin{array}{c}0.08 \\
(0.03)\end{array}$ & 0.92 \\
\hline
\end{tabular}

Standard errors in parentheses

Note: $\quad$ This table provides a pairwise t-test of self-reported social network variables at baseline, between farmers selected for treatment and those in the control group. Each variable is the share of the people, among a random selection of other farmers in the production block, for whom a farmer answered yes to that survey question.

Of course, the effect of the treatment on social connectedness matters only if connectedness itself is actually related to the variable of interest-participation in kombits. Table 17 shows that this is the case. All of the social network variables are correlated with greater participation in canal cleaning days. To interpret the magnitude of the coefficients, we can think about the typical farmer who has four other farmers in his group. An increase of one person with whom the farmer says he shares advice on farming — a 0.25 increase in the share - is associated with an increase in the probability of kombit participation of three percentage points. This is a substantial increase given the participation rate of $9.3 \%$ among control-group farmers, implying that one new connection with a neighbor is associated with a $32 \%$ increase in kombit participation.

Although I fail to find convincing evidence that supports a technical mechanism driving the treatment effect, I do find support for social mechanisms operating through both norms and social networks. These two mechanisms are not mutually exclusive; farmers may be learning both about the technical relationship between canal function and yields and about their neighbors. And although I fail to reject the null hypothesis that there is no impact on learning, we cannot rule out that learning may also play a role in the treatment effect we see. 
Table 17. Effect of social networks on kombit participation

\begin{tabular}{|c|c|c|c|c|}
\hline Dependent variable: Particp & $\begin{array}{c}\text { mbits (0/ } \\
\text { (1) }\end{array}$ & (2) & (3) & (4) \\
\hline Knows plot neighbors & $\begin{array}{c}0.056 \\
(0.039)\end{array}$ & & & \\
\hline Asks/gives farm advice & & $\begin{array}{l}0.12^{\star \star \star} \\
(0.036)\end{array}$ & & \\
\hline Shares labor & & & $\begin{array}{c}0.14^{\star *} \\
(0.053)\end{array}$ & \\
\hline Any social network question & & & & $\begin{array}{l}0.11^{\star \star \star} \\
(0.040)\end{array}$ \\
\hline Constant & $\begin{array}{c}0.12 \\
(0.099)\end{array}$ & $\begin{array}{c}0.098 \\
(0.097)\end{array}$ & $\begin{array}{c}0.11 \\
(0.097)\end{array}$ & $\begin{array}{c}0.088 \\
(0.098)\end{array}$ \\
\hline Household controls & Yes & Yes & Yes & Yes \\
\hline Observations & 600 & 600 & 600 & 600 \\
\hline Adjusted $\mathrm{R}^{2}$ & 0.060 & 0.073 & 0.071 & 0.069 \\
\hline
\end{tabular}

Standard errors (in parentheses) clustered at the group level

${ }^{*} p<.1,{ }^{* *} p<.05,{ }^{* * *} p<.01$

Note: This table shows the treatment effect of each social network variable (defined as the share of the people in a farmer's geographic cluster for whom that farmer answered yes to that survey question) on the probability of a farmer participating in a kombit.

\section{VII.CONCLUSION}

This paper examines whether experimental lab-in-the-field games can serve as a pedagogical tool to change real-world behavior in a context similar to that modeled in the games. Previous studies have connected in-game behavior to real-world decisions. However, using games to influence decision making outside of the game is a new area of research that could be promising for policy interventions aimed at changing behavior in contexts in which individual incentives and socially optimal outcomes are not aligned.

Voluntary contributions to a public good provide just one example of a setting in which behavior often does not conform to neoclassical predictions: We often see, in experiments and in the real world, that people contribute and cooperate at a higher rate than one might predict solely on the basis of financial returns expected from cooperation. Such behavior is highly variable across different settings, so behavioral interventions aimed at increasing public goods contributions can improve welfare substantially in settings where such contributions are suboptimal.

In this study I have found that exposure to PG games designed to replicate the strategic considerations farmers face in the real world increases the average probability of their contributing to the public good by approximately $47 \%$. In terms of the total amount of labor contributed to canal cleaning, the treatment doubled the average contribution. Measuring a direct effect on physical canal performance was not possible given the experimental design, but this finding is a first step in demonstrating the possible effectiveness of experimental games as a way 
to shift behavior, at least in the short run. To put the increase into context, farmers estimated in survey responses that the observed increase in average contributions to canal cleaning would improve the performance of the canals enough to increase average yields on their plots by more than $10 \%$.

By examining in-game behavior and survey data, I provide suggestive evidence supporting the hypothesis that the treatment effect is operating through a social mechanism. Farmers who learned that their neighbors were likely to be high contributors increased their real-world contributions, although we do not observe a treatment effect for those who learned that their neighbors were not likely to contribute. This finding suggests that farmers are learning something about the other farmers with whom they share canals that determines how they will interpret the lessons of the game: Those who learn that others are likely to contribute, in turn contribute more themselves. Additionally, we see an effect on social networks among treated farmers. Participation in the games increased connectedness among farmers who cultivate plots near one another, and social connectedness to neighboring farmers is a strong predictor of contributions to the public good.

The evidence I provide in this paper suggests that experimental games could be a valuable tool to be used in development interventions to increase collective action around public goods provision. Conducting PG games can be inexpensive if run by local partners for the purpose of learning, rather than for rigorous data collection. In fact, during the course of this research, the president of the local irrigation association asked to be trained in running the games in subsequent years because he saw their value as a possible way to motivate farmers to participate in canal cleaning. More research is needed to explore the longer-term impacts of such an intervention and to explore more rigorously the mechanisms behind the treatment effect, to help us understand better why such an intervention works and how long we can expect the effects to last. 


\section{REFERENCES}

Allcott, H., and T. Rogers. 2014. "The Short-Run and Long-Run Effects of Behavioral Interventions: Experimental Evidence from Energy Conservation.” American Economic Review, vol. 104, 2014, pp. 3003-37.

Andreoni, J. 1990. "Impure Altruism and Donations to Public Goods: A Theory of Warm-Glow Giving.” The Economic Journal, 1990, pp. 464-477.

Avdeenko, A., and M. J. Gilligan. "International Interventions to Build Social Capital: Evidence from a Field Experiment in Sudan.” Working paper No. 6772. Washington, DC: World Bank Policy Research, 2014.

Baland, J. M., and J. P. Platteau. "Wealth Inequality and Efficiency in the Commons, Part II: The Regulated Case.” Oxford Economic Papers, vol. 50, 1998, pp. 1-22.

Barr, A. "Trust and Expected Trustworthiness: Experimental Evidence from Zimbabwean Villages.” The Economic Journal, vol. 113, 2003, pp. 614-630.

Beath, A., F. Christia, and R. Enikolopov. "Do Elected Councils Improve Governance? Experimental Evidence on Local Institutions in Afghanistan.” 2013.

Besley, T., and A. Case. "Modeling Technology Adoption in Developing Countries.” The American Economic Review, 1993, vol. 83, no. 2, 1993, pp. 396-402.

Bó, P. D., and G. R. Fréchette. “The Evolution of Cooperation in Infinitely Repeated Games: Experimental Evidence.” The American Economic Review, vol. 101, 2011, pp. 411-429.

Cárdenas, J. C., and J. Carpenter. "Three Themes on Field Experiments and Economic Development.” In Field Experiments in Economics (Research in Experimental Economics, Volume 10), edited by Jeffrey P. Carpenter, Glenn W. Harrison, and John A. List. Bingley, UK: Emerald Group Publishing, 2005.

Cárdenas, J. C., L. A. Rodriguez, and N. Johnson. "Collective Action for Watershed Management: Field Experiments in Colombia and Kenya.” Environment and Development Economics, vol. 16, 2011, pp. 275-303.

Carter, M. R., and M. Castillo. "Trustworthiness and Social Capital in South Africa: Analysis of Actual Living Standards Data and Artifactual Field Experiments.” Economic Development and Cultural Change, vol. 59, 2011, pp. 695-722.

Casey, K., R. Glennerster, and E. Miguel. "Reshaping Institutions: Evidence on Aid Impacts Using a Preanalysis Plan.” The Quarterly Journal of Economics, vol. 127, no. 4, 2012, pp. 1755-1812.

Chaudhuri, A. "Sustaining Cooperation in Laboratory Public Goods Experiments: A Selective Survey of the Literature.” Experimental Economics, vol. 14, 2011, pp. 47-83. 
Conley, T., and C. Udry. "Social Learning Through Networks: The Adoption of New Agricultural Technologies in Ghana.” American Journal of Agricultural Economics, vol. 83, 2001, pp. 668-673.

Duffy, J., and J. Ochs. “Cooperative behavior and the frequency of social interaction.” Games and Economic Behavior, vol. 66, 2009, pp. 785-812.

Fearon, J. D., M. Humphreys, and J. M. Weinstein. “Can Development Aid Contribute to Social Cohesion After Civil War? Evidence from a Field Experiment in Post-Conflict Liberia.” The American Economic Review, vol. 99, no. 2, 2009, pp. 287-291.

Ferraro, P. J., and M. K. Price. "Using Nonpecuniary Strategies to Influence Behavior: Evidence from a Large-Scale Field Experiment.” Review of Economics and Statistics, vol. 95, 2013, pp. 64-73.

Fischbacher, U., S. Gächter, and E. Fehr. “Are People Conditionally Cooperative? Evidence from a Public Goods Experiment.” Economics Letters, vol. 71, 2001, pp. 397-404.

Foster, A. D., and M. R. Rosenzweig. "Learning by Doing and Learning from Others: Human Capital and Technical Change in Agriculture.” Journal of Political Economy, vol. 103, 1995, pp. 1176-1209.

Hanna, R., S. Mullainathan, and J. Schwartzstein. "Learning Through Noticing: Theory and Evidence from a Field Experiment.” The Quarterly Journal of Economic, vol. 129, 2014, pp. 1311-1353.

Hardin, G. “The tragedy of the commons.” Science, vol. 162, 1968, pp. 1243-1248.

Henrich, J., R. Boyd, S. Bowles, C. Camerer, E. Fehr, H. Gintis, and R. McElreath. "In Search of Homo Economicus: Behavioral Experiments in 15 Small-Scale Societies.” American Economic Review, vol. 91, 2001, pp. 73-78.

Hess, C. A Comprehensive Bibliography of Common Pool Resources. Bloomington: Indiana University, Workshop in Political Theory and Policy Analysis, 1999.

Hoff, K., and P. Pandey. “Discrimination, Social Identity, and Durable Inequalities.” The American Economic Review, vol. 92, no. 2, 2006, pp. 206-211.

Isaac, R. M., J. M. Walker, and A. W. Williams. "Group Size and the Voluntary Provision of Public Goods: Experimental Evidence Utilizing Large Groups.” Journal of Public Economics, vol. 54, 1994, pp. 1- 36.

Karlan, D. S. "Using Experimental Economics to Measure Social Capital and Predict Financial Decisions.” American Economic Review, vol. 95, no. 5, 2005, pp. 1688-1699.

Labonne, J., and R. S. Chase. "Do Community-Driven Development Projects Enhance Social Capital? Evidence from the Philippines.” Journal of Development Economics, vol. 96, 2011, pp. 348-358. 
Ledyard, J. O. "Public Goods: A Survey of Experimental Research.” In The Handbook of Experimental Economics, edited by J. H. Kagel and A. E. Roth, Princeton, NJ: Princeton University Press, 1995.

Mansuri, G., and V. Rao. Localizing Development: Does Participation Work? Washington, DC: World Bank Publications, 2012.

McCarthy, N., E. Sadoulet, and A. de Janvry. “Common Pool Resource Appropriation Under Costly Cooperation.” Journal of Environmental Economics and Management, vol. 42, no. 3, 2001, pp. 297-309.

Moser, C. M., and C. B. Barrett. "The Disappointing Adoption Dynamics of a Yield-Increasing, Low External-Input Technology: The Case of SRI in Madagascar.” Agricultural Systems, vol. 76. 2003, pp. 1085-1100.

Ostrom, E. “Collective Action and the Evolution of Social Norms.” Journal of Natural Resources Policy Research, vol. 6, 2014, pp. 235-252.

Ostrom, E. Governing the Commons: The Evolution of Institutions for Collective Action. Cambridge, UK: Cambridge University Press, 1990.

Pretty, J. “Social Capital and the Collective Management of Resources.” Science, vol. 302, 2003, pp. 1912-1914.

Roth, A. E., V. Prasnikar, M. Okuno-Fujiwara, and S. Zamir. "Bargaining and Market Behavior in Jerusalem, Ljubljana, Pittsburgh, and Tokyo: An Experimental Study.” The American Economic Review, vol. 81, 1991, pp. 1068-1095.

Sethi, R., and E. Somanathan. "The Evolution of Social Norms in Common Property Resource Use.” The American Economic Review, vol. 86, no. 4, 1996, pp. 766-788.

Sinha, S. K., and J. Talati. "Productivity Impacts of the System of Rice Intensification (SRI): A Case Study in West Bengal, India.” Agricultural Water Management, vol. 87, 2007, pp. 5560 .

Stoop, W. A., N. Uphoff, and A. Kassam. “A Review of Agricultural Research Issues Raised by the System of Rice Intensification (SRI) from Madagascar: Opportunities for Improving Farming Systems for Resource-Poor Farmers.” Agricultural Systems, vol. 71, 2002, pp. 249_ 274.

Takahashi, K., and C. B. Barrett. "The System of Rice Intensification and Its Impacts on Household Income and Child Schooling: Evidence from Rural Indonesia.” American Journal of Agricultural Economics, vol. 96, 2014, pp. 269-289.

Voors, M. J., and E. H. Bulte. "Conflict and the Evolution of Institutions: Unbundling Institutions at the Local Level in Burundi.” Journal of Peace Research, vol. 51, 2014, pp. 455-469. 
Zwane, A. P., J. Zinman, E. Van Dusen, W. Pariente, C. Null, E. Miguel, M. Kremer, D. S. Karlan, R. Hornbeck, X. Giné, E. Duflo, F. Devoto, B. Crepon, and A. Banerjee. "Being Surveyed Can Change Later Behavior and Related Parameter Estimates.” Proceedings of the National Academy of Sciences, vol. 108, 2011, pp. 1821-1826. 


\section{ABOUT THE SERIES}

Policymakers and researchers require timely, accurate, evidence-based research as soon as it's available. Further, statistical agencies need information about statistical techniques and survey practices that yield valid and reliable data. To meet these needs, Mathematica's working paper series offers access to our most current work.

For more information about this paper, contact Abbie Turiansky, Researcher, at aturiansky@mathematic-mpr.com.

Suggested citation: Turiansky, Abbie. "Collective Action in Games as in Life: Experimental Evidence from Canal Cleaning in Haiti.” Working Paper \#57. Oakland: Mathematica Policy Research, November 2017. 
www.mathematica-mpr.com

Improving public well-being by conducting high quality, objective research and data collection

PRINCETON, NJ - ANN ARBOR, MI - CAMBRIDGE, MA - CHICAGO, IL - OAKLAND, CA SEATTLE, WA - TUCSON, AZ - WASHINGTON, DC - WOODLAWN, MD 